\title{
The CSIRO Mk3L climate system model version 1.0 - Part 1: Description and evaluation
}

\author{
S. J. Phipps ${ }^{1,2,3,4}$, L. D. Rotstayn ${ }^{5}$, H. B. Gordon ${ }^{5}$, J. L. Roberts ${ }^{2,3,6}$, A. C. Hirst ${ }^{5}$, and W. F. Budd ${ }^{1,2,3}$ \\ ${ }^{1}$ Institute of Antarctic and Southern Ocean Studies, University of Tasmania, Australia \\ ${ }^{2}$ Antarctic Climate \& Ecosystems CRC, Hobart, Tasmania, Australia \\ ${ }^{3}$ Tasmanian Partnership for Advanced Computing, Hobart, Tasmania, Australia \\ ${ }^{4}$ Climate Change Research Centre, University of New South Wales, Australia \\ ${ }^{5}$ Centre for Australian Weather and Climate Research: A partnership between CSIRO and the Bureau of Meteorology, \\ Aspendale, Victoria, Australia \\ ${ }^{6}$ Australian Antarctic Division, Kingston, Tasmania, Australia
}

Received: 14 January 2011 - Published in Geosci. Model Dev. Discuss.: 1 February 2011

Revised: 31 May 2011 - Accepted: 7 June 2011 - Published: 17 June 2011

\begin{abstract}
The CSIRO Mk3L climate system model is a coupled general circulation model, designed primarily for millennial-scale climate simulations and palaeoclimate research. Mk3L includes components which describe the atmosphere, ocean, sea ice and land surface, and combines computational efficiency with a stable and realistic control climatology. This paper describes the model physics and software, analyses the control climatology, and evaluates the ability of the model to simulate the modern climate.

Mk3L incorporates a spectral atmospheric general circulation model, a $z$-coordinate ocean general circulation model, a dynamic-thermodynamic sea ice model and a land surface scheme with static vegetation. The source code is highly portable, and has no dependence upon proprietary software. The model distribution is freely available to the research community. A 1000-yr climate simulation can be completed in around one-and-a-half months on a typical desktop computer, with greater throughput being possible on highperformance computing facilities.

Mk3L produces realistic simulations of the larger-scale features of the modern climate, although with some biases on the regional scale. The model also produces reasonable representations of the leading modes of internal climate variability in both the tropics and extratropics. The control state of the model exhibits a high degree of stability, with only a weak cooling trend on millennial timescales. Ongoing development work aims to improve the model climatology and transform Mk3L into a comprehensive earth system model.
\end{abstract}

Correspondence to: S. J. Phipps

(s.phipps@unsw.edu.au)

\section{Introduction}

The CSIRO Mk3L climate system model is a computationally-efficient atmosphere-land-sea ice-ocean general circulation model, designed for the study of climate variability and change on millennial timescales. It represents a new version of the CSIRO climate model, the history of which is described by Smith (2007). The atmosphere, land and sea ice models are reduced-resolution versions of those used by the CSIRO Mk3 coupled model (Gordon et al., 2002), which contributed towards CMIP3 (Meehl et al., 2007) and the IPCC Fourth Assessment Report (Solomon et al., 2007). The ocean model is taken from the CSIRO Mk2 coupled model (Gordon and O'Farrell, 1997), which contributed towards CMIP2 (Meehl et al., 2000) and the IPCC Third Assessment Report (Houghton et al., 2001). This combination produces a coupled climate system model that has both a realistic control climatology and very fast execution times.

The spatial resolution of $\mathrm{Mk} 3 \mathrm{~L}$ is similar to that of reduced-resolution versions of other IPCC-class climate models, including FAMOUS, which is a low-resolution version of HadCM3 (Cox et al., 2000; Jones, 2003; Jones et al., 2005), and low-resolution versions of CCSM3 (Yeager et al., 2006) and the GFDL coupled climate model (Dixon et al., 2003). The resolution is also the same as that of another reduced-resolution version of the CSIRO climate model (Mk3A; Rotstayn et al., 2007). In contrast to EMICs (Earth system Models of Intermediate Complexity; Claussen et al., 2002), such reduced-resolution models retain full atmospheric and oceanic physics. They are therefore capable of producing reasonable representations of the modes of internal climate variability. However, their computational

Published by Copernicus Publications on behalf of the European Geosciences Union. 
efficiency allows new classes of scientific problems to be studied. Reduced-resolution models can be used, for example, to generate transient simulations of palaeoclimate epochs, to study the equilibrium response of the climate system to external forcings, or to carry out large ensembles of simulations.

The atmospheric component of Mk3L is a spectral general circulation model with a reduced horizontal resolution of $\mathrm{R} 21$. This gives zonal and meridional resolutions of $5.625^{\circ}$ and $\sim 3.18^{\circ}$ respectively. A hybrid vertical coordinate is used, with 18 vertical levels. The model incorporates both a cumulus convection scheme and a prognostic stratiform cloud scheme. The radiation scheme simulates the full annual and diurnal cycles of longwave and shortwave radiation, and is able to calculate the cloud radiative forcings.

The land surface model employs a soil-canopy scheme and allows for 13 land surface and/or vegetation types and nine soil types. Prognostic soil and snow models describe the evolution of six soil layers and three snow layers, respectively. The vegetation types and land surface property distributions are pre-determined, however, and are therefore static.

The sea ice model includes both ice dynamics and ice thermodynamics. A cavitating fluid rheology is used to represent internal resistance to deformation, while the threelayer model of Semtner (1976) is used to represent the thermodynamics of ice and snow. Fractional ice cover is permitted, representing the presence of sub-gridscale leads and polynyas.

The oceanic component of $\mathrm{Mk} 3 \mathrm{~L}$ is a coarse-resolution, rigid-lid, $z$-coordinate general circulation model. The horizontal grid matches the Gaussian grid of the atmosphere model, and there are 21 vertical levels. The prognostic variables are potential temperature, salinity, and the zonal and meridional components of the horizontal velocity. The vertical velocity is diagnosed through the application of the continuity equation. The scheme of Gent and McWilliams (1990) is used to parameterise the adiabatic transport of tracers by mesoscale eddies.

When coupled, the atmospheric and oceanic components exchange fields every hour, ensuring that the model simulates diurnal cycles of sea surface temperature and salinity. Flux adjustments are applied to improve the realism of the control climate, and to ensure that it is stable on millennial timescales.

The model can be run in three different configurations: (i) the fully-coupled climate system model, (ii) a stand-alone atmosphere-land-sea ice model, or (iii) a stand-alone ocean model. The latter two modes are used primarily for the purpose of spinning up the model.

The source code has been designed to ensure that Mk3L is portable across a wide range of computer architectures, whilst also being computationally efficient. Dependence on external libraries is restricted to the netCDF and FFTW libraries, both of which are freely available and open source, while a high degree of shared-memory parallelism is achieved through the use of OpenMP directives. On an Intel Core 2 Duo processor, the coupled climate system model completes around 22 model years per day of walltime. Greater throughput can be achieved on high-performance computing facilities.

Mk3L is freely available to the research community for non-commercial purposes. A Subversion repository is used to manage the model distribution.

This paper describes version 1.0 of the CSIRO Mk3L climate system model, analyses the control climatology, and evaluates the ability of the model to simulate the modern climate. Section 2 describes the model physics, while Sect. 3 describes the model software and evaluates its computational performance. Section 4 describes the procedure used to initialise the climate system model, and the climatology of the model is evaluated in Sect. 5. The simulated internal variability is evaluated in Sect. 6, and the drift in the mean climate state is examined in Sect. 7. Plans for future development are discussed in Sect. 8.

A companion paper analyses the response of the model to external forcings. User documentation, as well as further information regarding the initial development of $\mathrm{Mk} 3 \mathrm{~L}$, is provided by Phipps (2006a).

\section{Model description}

\subsection{Atmosphere model}

The Mk3L atmosphere model is based on the atmospheric component of the CSIRO Mk3 coupled model (Gordon et al., 2002), but with the horizontal resolution reduced from spectral triangular T63 to spectral rhomboidal R21. The zonal and meridional resolutions of the model physics grid are therefore $5.625^{\circ}$ and $\sim 3.18^{\circ}$ respectively. The vertical resolution of 18 levels is retained.

The dynamical core of the atmosphere model is based upon the spectral method, and uses the flux form of the dynamical equations (Gordon, 1981). Physical parameterisations and non-linear dynamical flux terms are calculated on a latitude-longitude grid, with Fast Fourier Transforms used to map fields between their spectral and gridded forms. A fully-conservative semi-Lagrangian transport scheme is used to advect moisture (McGregor, 1993), while gravity wave drag is parameterised using the formulation of Chouinard et al. (1986).

A hybrid vertical coordinate is used, which is denoted as the $\eta$-coordinate. As in the $\sigma$-system, where $\sigma$ is the ratio of the pressure to the surface pressure, the Earth's surface forms the first coordinate surface. The remaining coordinate surfaces then gradually revert to isobaric levels with increasing altitude. The 18 vertical levels used in the Mk3L atmosphere model are listed in Table 1 (Gordon et al., 2002, Table 1).

The topography is derived by interpolating the $1^{\circ} \times 1^{\circ}$ dataset of Gates and Nelson (1975a) onto the model grid. 
Table 1. The hybrid vertical levels used within the Mk3L atmosphere model: the value of the $\eta$-coordinate, and the approximate height.

\begin{tabular}{ccc}
\hline $\begin{array}{l}\text { Level } \\
(k)\end{array}$ & $\eta$ & $\begin{array}{c}\text { Approximate } \\
\text { height }(\mathrm{m})\end{array}$ \\
\hline 18 & 0.0045 & 36355 \\
17 & 0.0216 & 27360 \\
16 & 0.0542 & 20600 \\
15 & 0.1001 & 16550 \\
14 & 0.1574 & 13650 \\
13 & 0.2239 & 11360 \\
12 & 0.2977 & 9440 \\
11 & 0.3765 & 7780 \\
10 & 0.4585 & 6335 \\
9 & 0.5415 & 5070 \\
8 & 0.6235 & 3970 \\
7 & 0.7023 & 3025 \\
6 & 0.7761 & 2215 \\
5 & 0.8426 & 1535 \\
4 & 0.8999 & 990 \\
3 & 0.9458 & 575 \\
2 & 0.9784 & 300 \\
1 & 0.9955 & 165 \\
\hline & & \\
\end{tabular}

Some adjustments are then made so as to avoid areas of significant negative elevation upon fitting to the truncated resolution of the spectral model (Gordon et al., 2002). The resulting topography is shown in Fig. 1.

The radiation scheme treats solar (shortwave) and terrestrial (longwave) radiation independently. The default carbon dioxide concentration is $280 \mathrm{ppm}$, and the default ozone concentrations are taken from the AMIP II recommended dataset (Wang et al., 1995). The model does not account for the radiative effects of other anthropogenic greenhouse gases. The method of Berger (1978) is used to calculate the Earth's orbital parameters. The default values of the epoch and the solar constant are $1950 \mathrm{CE}$ and $1365 \mathrm{~W} \mathrm{~m}^{-2}$, respectively.

Full radiation calculations are conducted every two hours, allowing for both the annual and diurnal cycles. Clear-sky radiation calculations are also performed at each radiation timestep. This enables the cloud radiative forcings to be determined using Method II of Cess and Potter (1987), with the forcings being given by the differences between the radiative fluxes calculated with and without the effects of clouds.

The shortwave radiation scheme is based on the approach of Lacis and Hansen (1974), which divides the shortwave spectrum into 12 bands. Within each of these bands, the radiative properties are taken as being uniform. The longwave radiation scheme uses the parameterisation developed by Fels and Schwarzkopf (Fels and Schwarzkopf, 1975, 1981; Schwarzkopf and Fels, 1985, 1991), which divides the longwave spectrum (wavelengths longer than $5 \mu \mathrm{m}$ ) into seven bands.

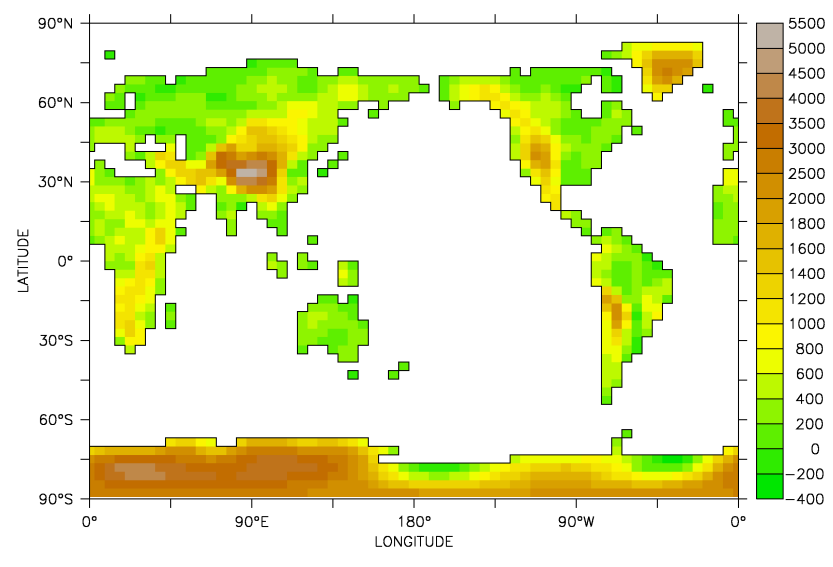

Fig. 1. The topography of the $\mathrm{Mk} 3 \mathrm{~L}$ atmosphere model: the elevation of land gridpoints $(\mathrm{m})$.

The planetary boundary layer is described using a modified version of the stability-dependent scheme of Louis (1979). The scheme of Holtslag and Boville (1993) is used to incorporate the nonlocal effects of large eddy transport.

The cumulus convection scheme is based on the UK Meteorological Office scheme (Gregory and Rowntree, 1990), and generates both the amount and the liquid water content of convective clouds. This scheme is coupled to the prognostic cloud scheme of Rotstayn (1997, 1998) and Rotstayn et al. (2000), which calculates the amount of stratiform cloud using the three prognostic variables of water vapour mixing ratio, cloud liquid water mixing ratio and cloud ice mixing ratio.

Time integration is via a leapfrog time integration scheme, with a Robert-Asselin time filter (Robert, 1966) used to prevent decoupling of the time-integrated solutions at odd and even timesteps. A semi-implicit treatment of gravity waves increases the maximum permissible timestep duration. The main timestepping loop is executed once every $20 \mathrm{~min}$, with the physics and dynamics calculations being conducted every timestep. However, full radiation calculations are only conducted once every six timesteps. At each of the intervening timesteps, the atmospheric heating rates are held constant, but the upward longwave and downward shortwave fluxes at the surface are re-calculated in order to smooth the diurnal cycle of net radiation.

In the stand-alone atmosphere model, four types of surface gridpoint are employed: land, sea, mixed-layer ocean and sea ice. The temperatures of the sea gridpoints are determined by monthly-mean observed sea surface temperatures. Linear interpolaton in time is used to estimate values at each timestep, with no allowance for any diurnal variation. At high latitudes, sea gridpoints may be converted to mixed-layer ocean gridpoints, with self-computed temperatures; these can then evolve into sea ice gridpoints. This is discussed further in the description of the sea ice model (Sect. 2.3). 
Table 2. The thickness of the soil layers used within the Mk3L land surface model.

\begin{tabular}{lc}
\hline $\begin{array}{l}\text { Level } \\
(k)\end{array}$ & $\begin{array}{c}\text { Thickness } \\
(\mathrm{m})\end{array}$ \\
\hline 1 & 0.022 \\
2 & 0.058 \\
3 & 0.154 \\
4 & 0.409 \\
5 & 1.085 \\
6 & 2.872 \\
\hline
\end{tabular}

\subsection{Land surface model}

The land surface model is an enhanced version of the soilcanopy scheme of Kowalczyk et al. (1991, 1994). A new parameterisation of soil moisture and temperature has been implemented, a greater number of soil and vegetation types are available, and a multi-layer snow cover scheme has been incorporated (Gordon et al., 2002). The land surface model uses the same horizontal grid and timestepping as the atmosphere model. The zonal and meridional resolutions are therefore $5.625^{\circ}$ and $\sim 3.18^{\circ}$, respectively, with a timestep of $20 \mathrm{~min}$.

The soil-canopy scheme allows for 13 land surface and/or vegetation types and nine soil types. The land surface property distributions are pre-determined, with seasonallyvarying values being provided for the albedo and roughness length, and annual-mean values for the vegetation fraction. A seasonally-varying stomatal resistance is calculated by the model, subject to a specified minimum value. The soil model has six layers, the thicknesses of which are shown in Table 2. The total depth of the soil column at all gridpoints is $4.6 \mathrm{~m}$. Soil temperature and the liquid water and ice contents are calculated as prognostic variables. Run-off occurs once the surface layer becomes saturated, and is assumed to travel instantaneously to the ocean via the path of steepest descent.

The snow model computes the temperature, snow density and thickness of three snowpack layers, as well as the snow albedo. The maximum snow depth is set at $4 \mathrm{~m}$, with any excess snowfall being converted to run-off. When snow is present, the model also reduces the vegetation fraction for some vegetation types, to allow for vegetation being partially or completely buried by snow. Ice sheets are not explicitly represented, although there are land surface and soil types that reflect the presence of perennial ice cover.

\subsection{Sea ice model}

The sea ice model includes both ice dynamics and ice thermodynamics, and is described by O'Farrell (1998). Internal resistance to deformation is parameterised using the cavitating fluid rheology of Flato and Hibler (1990, 1992). The thermodynamic component is based on the model of Semtner (1976), which splits the sea ice into three layers, one for snow and two for ice. Sea ice gridpoints are allowed to have fractional ice cover, representing the presence of subgridscale leads and polynyas. The sea ice model uses the same horizontal grid as the atmosphere model, and the zonal and meridional resolutions are therefore $5.625^{\circ}$ and $\sim 3.18^{\circ}$ respectively. A timestep of $1 \mathrm{~h}$ is used.

Ice advection arises from the forcing from above by atmospheric wind stresses, and from below by oceanic currents. When running as part of the coupled climate system model, the currents are obtained from the ocean model; in standalone mode, the currents are determined using a monthly climatology, with linear interpolation in time being used to estimate values at each timestep.

The advance and retreat of the ice edge in the standalone atmosphere-land-sea ice model is controlled by using a mixed-layer ocean model to compute water temperatures for those sea gridpoints which lie adjacent to sea ice (Gordon et al., 2002). The mixed-layer ocean has a fixed depth of $100 \mathrm{~m}$, and the evolution of the water temperature is determined using the surface heat flux terms and a weak relaxation towards the prescribed sea surface temperature. The relaxation timescale used is 23 days. A mixed-layer ocean gridpoint can become a sea ice gridpoint either when its temperature falls below the freezing point of seawater, which is taken as being $-1.85^{\circ} \mathrm{C}$, or when ice is advected into it from an adjacent sea ice gridpoint. When a mixed-layer ocean gridpoint is converted to a sea ice gridpoint, the initial ice concentration is set to $4 \%$. The neighbouring equatorward gridpoint, if it is a sea gridpoint, is then converted to a mixedlayer ocean gridpoint.

Surface processes can increase the ice thickness through the conversion of snow to ice. When the depth of the snow cover exceeds $2 \mathrm{~m}$, the excess is converted into an equivalent amount of ice. Alternatively, when the weight of snow becomes so great that the floe becomes completely submerged, any submerged snow is converted into "white" ice. Surface processes can also reduce the ice thickness through melting and sublimation.

Lateral and basal ice growth and melt are determined by the temperature of the mixed-layer ocean. Additional ice can grow when the water temperature falls below the freezing point of seawater, $-1.85^{\circ} \mathrm{C}$, subject to a maximum allowable thickness of $6 \mathrm{~m}$. Once the water temperature rises above $-1.5^{\circ} \mathrm{C}$, half of any additional heating is used to melt ice; once it rises above $-1.0^{\circ} \mathrm{C}$, all of the additional heating is used to melt ice. In the stand-alone atmosphere-land-sea ice model, a sea ice gridpoint is converted back to a mixed-layer ocean gridpoint once the sea ice has disappeared. The neighbouring equatorward gridpoint, if it is a mixed-layer ocean gridpoint, is then converted back to a sea gridpoint. 
Table 3. The vertical levels used within the Mk3L ocean model: the thickness, the depth of the centre and base of each gridbox, and the value of the isopycnal thickness diffusivity.

\begin{tabular}{cccrr}
\hline $\begin{array}{l}\text { Level } \\
(k)\end{array}$ & Thickness & \multicolumn{2}{c}{ Depth $(\mathrm{m})$} & $\kappa_{\mathrm{e}}$ \\
& $(\mathrm{m})$ & Centre & Base & $\left(\mathrm{m}^{2} \mathrm{~s}^{-1}\right)$ \\
\hline 1 & 25 & 12.5 & 25 & $0^{*}$ \\
2 & 25 & 37.5 & 50 & $70^{*}$ \\
3 & 30 & 65 & 80 & $180^{*}$ \\
4 & 37 & 98.5 & 117 & $290^{*}$ \\
5 & 43 & 138.5 & 160 & $420^{*}$ \\
6 & 50 & 185 & 210 & $580^{\dagger}$ \\
7 & 60 & 240 & 270 & $770^{\dagger}$ \\
8 & 80 & 310 & 350 & $1000^{\ddagger}$ \\
9 & 120 & 410 & 470 & $1000^{\ddagger}$ \\
10 & 150 & 545 & 620 & $1000^{\ddagger}$ \\
11 & 180 & 710 & 800 & $1000^{\ddagger}$ \\
12 & 210 & 905 & 1010 & $1000^{\ddagger}$ \\
13 & 240 & 1130 & 1250 & $1000^{\ddagger}$ \\
14 & 290 & 1395 & 1540 & $1000^{\ddagger}$ \\
15 & 360 & 1720 & 1900 & $1000^{\ddagger}$ \\
16 & 450 & 2125 & 2350 & $1000^{\ddagger}$ \\
17 & 450 & 2575 & 2800 & $1000^{\ddagger}$ \\
18 & 450 & 3025 & 3250 & $1000^{\ddagger}$ \\
19 & 450 & 3475 & 3700 & $1000^{\ddagger}$ \\
20 & 450 & 3925 & 4150 & $1000^{\ddagger}$ \\
21 & 450 & 4375 & 4600 & $1000^{\ddagger}$ \\
\hline & & & &
\end{tabular}

\footnotetext{
* These values are fixed.

$\dagger$ These are the maximum allowable values; however, lower values may be specified by the user.

$\ddagger$ These are the default values; however, alternative values may be specified by the user.
}

\subsection{Ocean model}

The Mk3L ocean model is a coarse-resolution, rigid-lid, $z$ coordinate general circulation model, based on the oceanic component of the CSIRO Mk2 coupled model (Gordon and O'Farrell, 1997; Hirst et al., 2000; Bi et al., 2001, 2002). The CSIRO ocean model is, in turn, based on the implementation by Cox (1984) of the primitive equation numerical model of Bryan (1969).

The prognostic variables calculated by the model are potential temperature, salinity, and the zonal and meridional components of the horizontal velocity. The Arakawa B-grid (Arakawa and Lamb, 1977) is used, in which the tracer gridpoints are located at the centres of the gridboxes and the horizontal velocity gridpoints are located at the corners. The vertical velocity is diagnosed through application of the continuity equation, which enforces conservation of mass in an incompressible fluid.

The model uses a longitude-latitude grid, with walls at the north and south poles. The horizontal grid matches the Gaussian grid of the atmosphere model, such that the tracer gridpoints on the ocean model grid coincide with the grid-

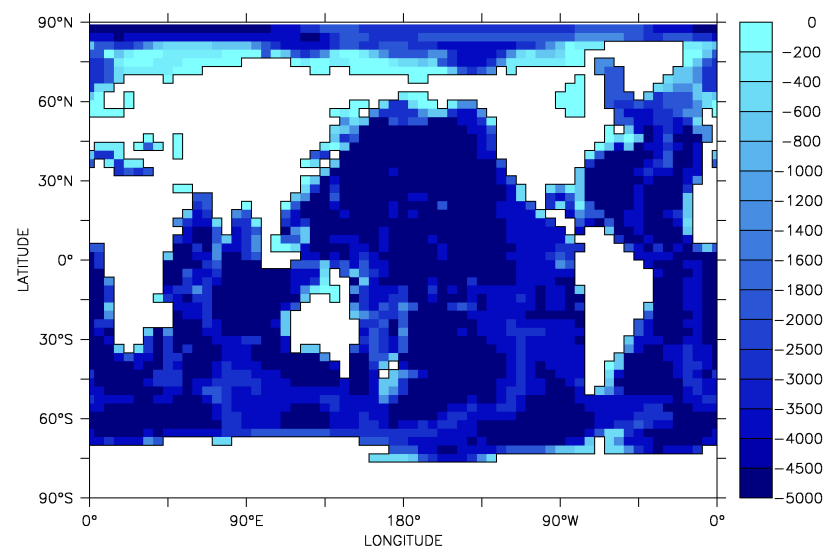

Fig. 2. The bathymetry of the Mk3L ocean model: the depth of ocean gridpoints $(\mathrm{m})$.

points on the atmosphere model physics grid. The zonal and meridional resolutions are therefore $5.625^{\circ}$ and $\sim 3.18^{\circ}$, respectively. There are 21 vertical levels, which are listed in Table 3.

The bottom topography is derived by interpolating the $1^{\circ} \times 1^{\circ}$ dataset of Gates and Nelson (1975b) onto the model grid, with some slight smoothing to ensure that a solution is achieved when calculating the barotropic streamfunction (Cox, 1984). The resulting bathymetry is shown in Fig. 2.

The land/sea mask used by the ocean model differs from that used by the atmosphere model. The tips of South America and the Antarctic Peninsula are removed, ensuring that Drake Passage accommodates three horizontal velocity gridpoints. To ensure adequate resolution of the Greenland-Scotland sill, Iceland is also removed; likewise, a re-arrangement of the land/sea mask ensures adequate resolution of the flows through the Indonesian archipelago. Svalbard, which occupies a single isolated gridpoint on the atmosphere model grid, is not represented in the ocean model. Any straits that have a width of only one gridpoint on the tracer grid are closed, as these will not contain any horizontal velocity gridpoints. The Bass, Bering, Gibraltar, Hudson and Torres Straits, the Mozambique Channel and the Sea of Japan are therefore removed, while the Canadian archipelago becomes a land bridge.

The bathymetry defines six basins which have no resolved connection with the world ocean: the Baltic, Black, Caspian and Mediterranean Seas, Hudson Bay and the Persian Gulf. With the exception of the Caspian Sea, each of these basins exchanges water with the world ocean via straits which are not resolved on the model grid. The effects of these exchanges are parameterised within the model through an imposed mixing between the gridpoints which lie to either side of each unresolved strait.

Time integration is via a leapfrog scheme, with mixing timesteps conducted once every 19 tracer timesteps to 
Table 4. The computational performance of the Mk3L coupled climate system model: execution rates in model years per day of walltime.

\begin{tabular}{lcccc}
\hline Processor type & \multicolumn{5}{c}{ Number of cores } \\
and speed & 1 & 2 & 4 & 8 \\
\hline Intel Nehalem $2.93 \mathrm{GHz}$ & 15 & 28 & 48 & 74 \\
Intel Xeon 3.0 GHz & 14 & 22 & 33 & 50 \\
Intel Core 2 Duo 3.0 GHz & 13 & 22 & - & - \\
\hline
\end{tabular}

prevent decoupling of the time-integrated solutions at odd and even timesteps. Fourier filtering is used to reduce the timestep limitation arising from the CFL criterion (e.g., Washington and Parkinson, 1986) associated with the convergence of meridians at high latitudes, particularly in the Arctic Ocean (Cox, 1984). Fourier filtering is applied northward of $79.6^{\circ} \mathrm{N}$ in the case of tracers, and northward of $81.2^{\circ} \mathrm{N}$ in the case of horizontal velocities. The rigid-lid boundary condition (Cox, 1984) is employed to remove the timestep limitation associated with high-speed external gravity waves. The ocean bottom is assumed to be insulating, while no-slip and insulating boundary conditions are applied at lateral boundaries.

To reduce the execution time, the stand-alone ocean model employs an asynchronous timestepping scheme, with a timestep of 1 day used to integrate the tracer equations, and a timestep of $20 \mathrm{~min}$ used to integrate the momentum equations. However, asynchronous timestepping distorts the representation of time-dependent features such as Rossby Waves (Bryan, 1984). Within the coupled climate system model - and during the final stage of spin-up runs, prior to coupling to the atmosphere-land-sea ice model - a synchronous timestepping scheme is therefore employed, with a timestep of $1 \mathrm{~h}$ used to integrate both the tracer and momentum equations.

The vertical diffusivity varies as the inverse of the BruntVäisälä frequency, following the scheme of Gargett (1984). The minimum diffusivity is set to $3 \times 10^{-5} \mathrm{~m}^{2} \mathrm{~s}^{-1}$, except in the upper levels of the ocean, where it is increased to simulate the effects of mixing induced by surface winds. The minimum diffusivity between the upper two levels of the model is set to $2 \times 10^{-3} \mathrm{~m}^{2} \mathrm{~s}^{-1}$, while that between the second and third levels is set to $1.5 \times 10^{-4} \mathrm{~m}^{2} \mathrm{~s}^{-1}$. Whenever static instability arises, the vertical diffusivity is increased to $100 \mathrm{~m}^{2} \mathrm{~s}^{-1}$, simulating convective mixing; convection is therefore treated as a purely diffusive process.

Diffusion of tracers along surfaces of constant neutral density (isoneutral diffusion) is represented by the scheme of Cox (1987). In the default configuration of the model, the isoneutral diffusivity is set to the depth-independent value of $1000 \mathrm{~m}^{2} \mathrm{~s}^{-1}$. No background horizontal diffusion is applied.
The adiabatic transport of tracers by mesoscale eddies is represented by the scheme of Gent and McWilliams (1990) and Gent et al. (1995). An eddy-induced horizontal transport velocity is diagnosed, which is added to the resolved largescale horizontal velocity to give an effective horizontal transport velocity. The continuity equation can be used to derive the vertical component of either the eddy-induced transport velocity or the effective transport velocity. The default values for the isopycnal thickness diffusivity are shown in Table 3. Note that the values for levels 1 to 5 are fixed, and that upper limits are imposed on the values for levels 6 and 7. This decrease in the isopycnal thickness diffusivity in the upper layers, with a value of zero at the surface, is required by the continuity constraint imposed on the eddy-induced transport (e.g., Danabasoglu et al., 2008).

In the stand-alone ocean model, the temperature and salinity of the upper layer are relaxed towards prescribed values for the sea surface temperature (SST) and sea surface salinity (SSS). The default relaxation timescale is 20 days. Instantaneous values for the SST, SSS, and the zonal and meridional components of the surface wind stress, are determined from monthly climatologies, with linear interpolation in time being used to estimate values at each timestep.

\subsection{Coupled climate system model}

Within the Mk3L coupled climate system model, the atmosphere-land-sea ice model (AGCM) and ocean model (OGCM) exchange fields every $1 \mathrm{~h}$. This is in contrast to the approach employed by many other state-of-the-art climate system models, whereby fields are exchanged only once per day (e.g., Collins et al., 2006). More frequent coupling allows the model to explicitly resolve diurnal cycles in sea surface temperature and salinity. In other models, this has been found to improve the simulated climate in the tropics, with enhancements that include better representation of dynamical processes in the upper ocean, a reduction in the biases in sea surface temperature, an enhanced seasonal cycle, and better representations of the Madden-Julian Oscillation and El Niño-Southern Oscillation (Bernie et al., 2007, 2008; Danabasoglu et al., 2006).

The Mk3L coupled climate system model runs in a synchronous mode. One OGCM timestep $(1 \mathrm{~h})$ is followed by three AGCM timesteps $(3 \times 20 \mathrm{~min})$. Four fields are passed from the OGCM to the AGCM: the sea surface temperature (SST), sea surface salinity (SSS), and the zonal and meridional components of the surface velocity. Instantaneous values are passed for the surface velocity, and act as the bottom boundary condition on the sea ice model for the following three AGCM timesteps. The OGCM passes two copies of the SST and SSS fields, however: one containing the values at the current OGCM timestep, and one containing the values which have been predicted for the next OGCM timestep. The AGCM then uses linear interpolation in time to estimate the SST and SSS at each AGCM timestep. 
Four fields are also passed from the AGCM to the OGCM: the surface heat and salt fluxes, and the zonal and meridional components of the surface momentum flux. The surface fluxes are averaged over the three consecutive AGCM timesteps, before being passed to the OGCM. There is no allowance for penetrative solar radiation, with all of the energy supplied at the surface being added to the surface layer of the ocean. Mk3L employs a novel scheme to convert the surface freshwater flux to an equivalent salt flux, using the actual SSS at each gridpoint to perform the conversion, and applying a global offset to ensure conservation of freshwater (Phipps, 2006a).

Where there are mismatches between the positions of the coastlines on the AGCM and OGCM grids, spatial interpolation is used to estimate values of fields for locations where these fields are not defined on the source grid. Uniform offsets are applied to the interpolated fields to ensure that the global integrals are conserved.

Flux adjustments are applied within the coupled model for two reasons: to improve the realism of the simulated climate, and to minimise drift. Without them, the rate of climate drift is too large for the model to have utility on millennial timescales. The flux adjustments have a fixed annual cycle, and thus do not act to suppress internal variability. However, they arguably do limit the suitability of the model for studying climate states that represent large perturbations relative to the control state (Cubasch et al., 1992).

Following the approach of Sausen et al. (1988), adjustments are applied to each of the fluxes passed from the AGCM to the OGCM, and also to the SST and SSS. The need to apply adjustments to the surface velocities is avoided by employing a suitable spin-up procedure for the AGCM, whereby climatological values diagnosed from the OGCM are used.

\section{Software and computational performance}

The source code for $\mathrm{Mk} 3 \mathrm{~L}$ has been designed to ensure that the model is portable across a wide range of computer architectures. It is written entirely in Fortran, with a high degree of shared-memory parallelism being achieved through the use of OpenMP directives. Dependence on external libraries is restricted to the netCDF and FFTW libraries, both of which are freely available and open source. It has been verified that the model will compile and run correctly on a wide variety of Intel-based architectures, as well as on the Compaq Alpha and SGI Origin scalar architectures, and on the CRAY SV1 and NEC SX6 vector architectures.

To maximise the computational performance of the model, $\mathrm{Mk} 3 \mathrm{~L}$ is compiled and executed as a single program, with the coupling routines integrated into the source code for each of the component models. This approach eliminates the inefficiencies that can arise from load imbalances and the overheads associated with communication between different ex-
Table 5. Annual-mean surface air temperature $\left({ }^{\circ} \mathrm{C}\right)$ : $\mathrm{Mk} 3 \mathrm{~L}$ (average for years 201-1200), NCEP2 (1979-2003 average), and the model discrepancy (Mk3L minus NCEP2).

\begin{tabular}{lrrc}
\hline & Mk3L & NCEP2 & Discrepancy \\
\hline Globe & 13.62 & 14.41 & -0.79 \\
Land & 8.10 & 8.59 & -0.49 \\
Ocean & 15.91 & 16.73 & -0.82 \\
\hline
\end{tabular}

ecutables. However, it contrasts with the more modular approach employed by some other models (e.g., Collins et al., 2006), which compile and execute each component as a separate program.

Table 4 shows the computational performance of the Mk3L coupled climate system model on typical state-of-theart architectures for high-performance computing facilities (Intel Nehalem), servers (Intel Xeon) and desktop computers (Intel Core 2 Duo). The use of shared-memory parallelism, rather than distributed-memory parallelism, limits the number of cores on which the model can be run. However, very fast execution times can still be achieved, with a 1000-yr climate simulation able to be completed in as little as 13 days.

The Subversion revision control system is used to manage the model distribution. Mk3L is freely available to the research community, subject to the restriction that the model can only be used for non-commercial research purposes. Researchers can gain access to the Subversion repository by completing the online application form at http://www.tpac. org.au/main/csiromk31/.

\section{Spin-up procedure}

A multi-stage spin-up procedure is used to initialise the Mk3L climate system model: (i) the atmosphere-land-sea ice and ocean models are integrated separately until they reach equilibrium, (ii) the surface fluxes diagnosed from each spinup run are used to derive flux adjustments, (iii) the final states of each spin-up run are used to initialise the components of the climate system model, and (iv) the coupled climate system model is then integrated until it recovers from any initial adjustment. This section describes each stage of the procedure in detail.

As $\mathrm{Mk} 3 \mathrm{~L}$ is intended primarily for palaeoclimate studies, the pre-industrial climate is used as the control state of the model. To enable participation in model intercomparison projects and direct comparison with other climate system models, the spin-up procedure for $\mathrm{Mk} 3 \mathrm{~L}$ is consistent with PMIP2 experimental design (http://pmip2.lsce.ipsl.fr/). 


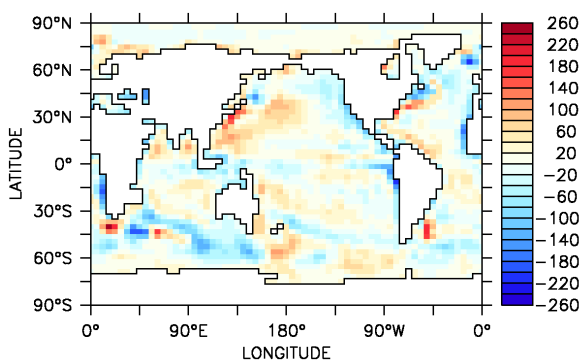

(a) Heat flux $\left(\mathrm{Wm}^{-2}\right)$

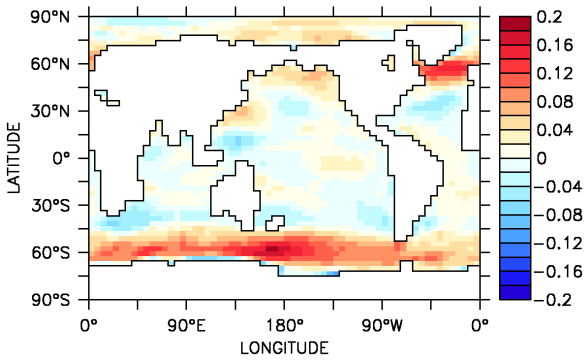

(c) Zonal wind stress $\left(\mathrm{Nm}^{-2}\right)$

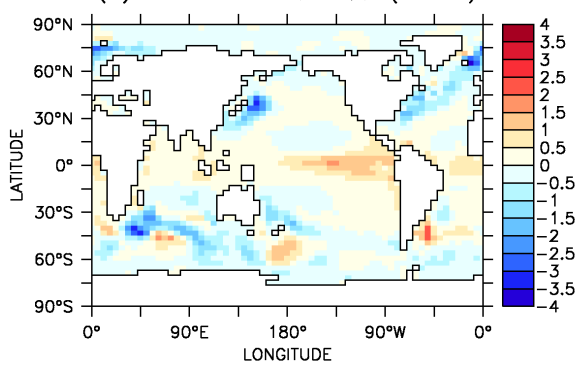

(e) Sea surface temperature (K)

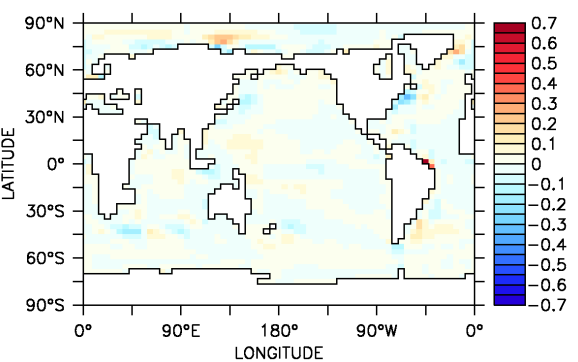

(b) Salt flux (m year $\left.{ }^{-1}\right)$

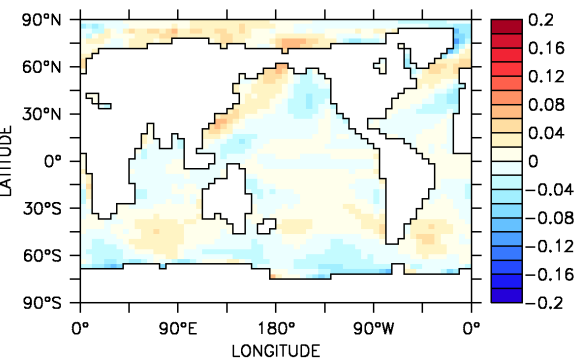

(d) Meridional wind stress $\left(\mathrm{Nm}^{-2}\right)$

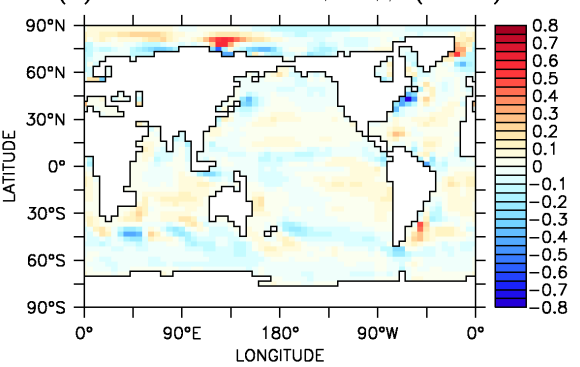

(f) Sea surface salinity (psu)

Fig. 3. The annual-mean values of the flux adjustments applied within the Mk3L coupled climate system model: (a) the surface heat flux, (b) the surface salt flux, $(\mathbf{c}, \mathbf{d})$ the zonal and meridional components of the surface wind stress, respectively, (e) the sea surface temperature, and (f) the sea surface salinity. For the surface fluxes, positive values indicate a downward flux.

\subsection{Ocean model}

The ocean model is first integrated to equilibrium. The model is initialised using the long-term annual-mean temperatures and salinities from the World Ocean Atlas 1998 dataset (Ocean Climate Laboratory, 1999), which is derived from observations spanning the period 1900-1997. It is then forced with climatological wind stresses derived from the NCEP-DOE Reanalysis 2 (Kanamitsu et al., 2002, hereafter referred to as NCEP2), while the temperature and salinity of the upper layer of the model are relaxed towards the World Ocean Atlas 1998 seasonal climatologies. The relaxation timescale used is 20 days.

The model is integrated for $4500 \mathrm{yr}$, using asynchronous timestepping for the first $4000 \mathrm{yr}$ and synchronous timestepping thereafter. Between the penultimate and final centuries of the simulation, the magnitudes of the changes in the mean temperature and salinity on each model level do not exceed $1.9 \times 10^{-3} \mathrm{~K}$ or $1.8 \times 10^{-4} \mathrm{psu}$, respectively. The final $100 \mathrm{yr}$ are used to diagnose climatological surface fields for the purposes of deriving flux adjustments.

\subsection{Atmosphere-land-sea ice model}

The atmosphere-land-sea ice model is integrated to equilibrium for pre-industrial conditions, using an atmospheric carbon dioxide concentration of $280 \mathrm{ppm}$, a solar constant of $1365 \mathrm{~W} \mathrm{~m}^{-2}$, and modern (1950 CE) values for the Earth's orbital parameters. World Ocean Atlas 1998 (Ocean Climate Laboratory, 1999) sea surface temperatures are applied as the bottom boundary condition, while the climatological ocean currents required by the sea ice model are diagnosed from the ocean model spin-up run.

The model is initialised from a previous spin-up run, and is integrated for $50 \mathrm{yr}$. The final $40 \mathrm{yr}$ are used to diagnose climatological surface fields for the purposes of deriving flux adjustments.

\subsection{Coupled climate system model}

The coupled climate system model is initialised from the final states of the atmosphere-land-sea-ice and ocean model simulations. For the purposes of this evaluation, it is then 
integrated for $4000 \mathrm{yr}$. The atmospheric carbon dioxide concentration and solar constant are held constant at $280 \mathrm{ppm}$ and $1365 \mathrm{~W} \mathrm{~m}^{-2}$, respectively, while modern values are used for the Earth's orbital parameters. Flux adjustments are applied.

The first $200 \mathrm{yr}$ of the simulation represent a spin-up period, and allow the model to recover from any initial adjustment. Years 201-1200 are used to characterise the control state of the model, and are analysed in Sects. 5 and 6. Later years are excluded from this analysis, so that it is not excessively affected by any long-term trends exhibited by the model. The full 4000-yr simulation is used to characterise any drift in the mean climate state, and is examined in Sect. 7.

\subsection{Flux adjustments}

The flux adjustments applied within the coupled climate system model are derived by subtracting the climatological surface fields diagnosed from the ocean model spin-up run from those diagnosed from the atmosphere-land-sea ice model spin-up run. The resulting adjustments have a fixed annual cycle.

Figure 3 shows the annual-mean values of the adjustments that are applied within the coupled climate system model. Over the open ocean, the values of the adjustments are generally small. Along the coastlines, heat flux adjustment terms arise from deficiencies in the representation of marine stratocumulus with the atmosphere model, and from the diffuse representation of the western boundary currents within the ocean model. Salt flux adjustment terms arise from discrepancies in the simulated rates of outflow for the major river systems, particularly the Amazon River. In the Southern Ocean, heat flux adjustment terms arise from the positioning of filaments of the Antarctic Circumpolar Current within the ocean model. Zonal wind stress adjustment terms arise from discrepancies between the strength of the Southern Hemisphere westerlies within the atmosphere model and within NCEP2, which is used to spin up the ocean model. Sea surface temperature and salinity adjustment terms arise from errors in the climatology of the ocean model; the use of the relaxation surface boundary condition to spin up the model means that the simulation must differ from the prescribed climatology in order for the model to simulate non-zero values for the surface fluxes (Phipps, 2006b).

\section{Mean climate}

In this section, the control climatology of the model is analysed, and the simulated mean climate is evaluated against observational and reanalysis datasets. These datasets document the modern state of the climate, and discrepancies between the model and observations may therefore arise from the use of a pre-industrial scenario as the control state of the model. Discrepancies may also arise from the assumption that the
Table 6. Annual-mean total cloud cover (percent): Mk3L (average for years 201-1200) and the Warren climatology.

\begin{tabular}{lcc}
\hline & Mk3L & Warren* \\
\hline Globe & 67.48 & 62.33 \\
Land & 55.43 & 56.41 \\
Ocean & 72.49 & 65.01 \\
\hline
\end{tabular}

* The Warren climatology only covers $98.0 \%$ of the Earth's surface.

pre-industrial climate was in equilibrium with the contemporary boundary conditions. In reality, the large thermal inertia of the deep ocean, in combination with the time-varying nature of boundary conditions such as the Earth's orbital parameters, ensures that the climate system can only ever be in a state of quasi-equilibrium (Weaver et al., 2000).

\subsection{Atmosphere}

\subsubsection{Surface air temperature}

Figure 4a,b shows the simulated annual-mean surface air temperature, and compares it with NCEP2. The root-meansquare error is $1.90 \mathrm{~K}$, with the model agreeing with the reanalysis to within $1 \mathrm{~K}$ over $56 \%$ of the Earth's surface, and to within $2 \mathrm{~K}$ over $85 \%$ of the Earth's surface. The only largescale discrepancy is over Western Antarctica, where it is too cold.

Figure $4 \mathrm{c}-\mathrm{f}$ shows the simulated mean surface air temperatures for December-January-February (DJF) and June-JulyAugust (JJA), and the discrepancies relative to NCEP2. The simulated winter temperatures over both polar regions are too cold, but otherwise the model is in good agreement with the reanalysis. The excessively warm winter temperatures over Hudson Bay are associated with the failure by the model to form sufficient sea ice cover in this region (Sect. 5.2).

The global-mean temperatures, and the means over land and over the ocean, are shown in Table 5. Although Mk3L is slightly cooler than NCEP2, the model was integrated for pre-industrial conditions while the NCEP2 values represent the 1979-2003 climatology. Indeed, the global-mean discrepancy of $-0.79 \mathrm{~K}$ is consistent with the observed globalmean surface air temperature increase of $0.76 \pm 0.19 \mathrm{~K}$ between 1850-1899 and 2001-2005 (Trenberth et al., 2007).

\subsubsection{Cloud}

Figure 5 shows the simulated annual-mean cloud cover, and compares it with the observed climatology of Warren et al. (1986, 1988) and Hahn et al. (1995), hereafter referred to as the Warren climatology. The simulated cloud cover is in good agreement with observations over land and over the high-latitude oceans. However, the model has excessive cloud cover over the tropical oceans, particularly in 


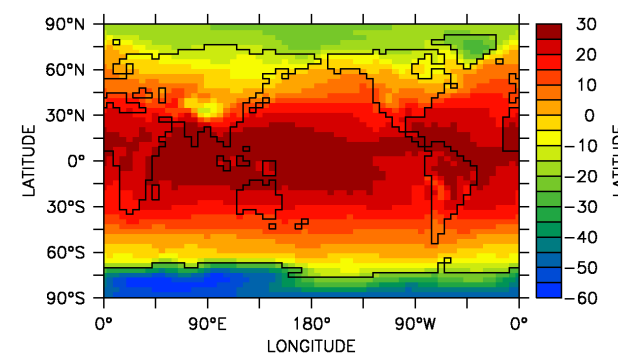

(a) Annual (Mk3L)

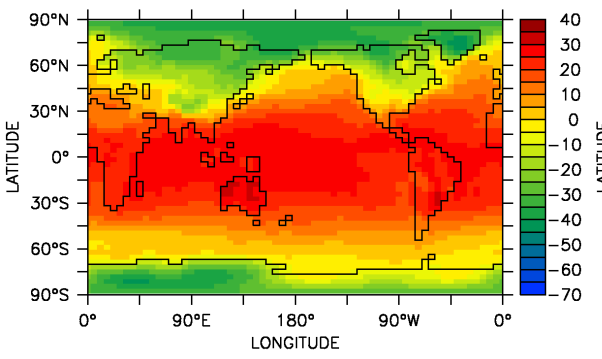

(c) DJF (Mk3L)

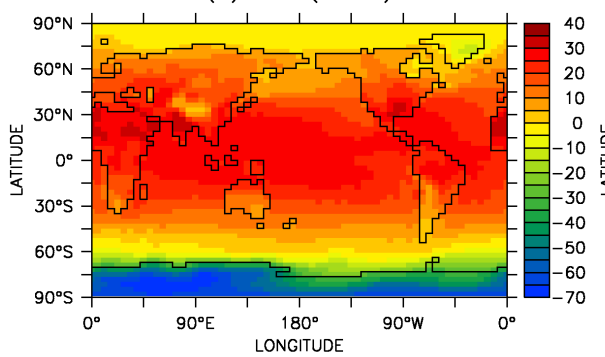

(e) JJA (Mk3L)

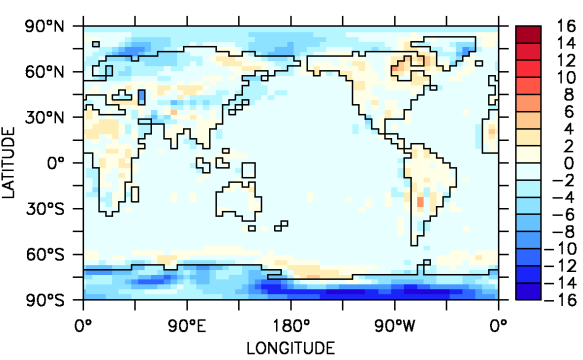

(b) Annual (Mk3L minus NCEP2)

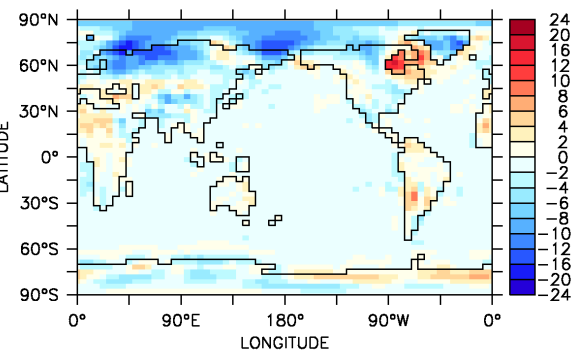

(d) DJF (Mk3L minus NCEP2)

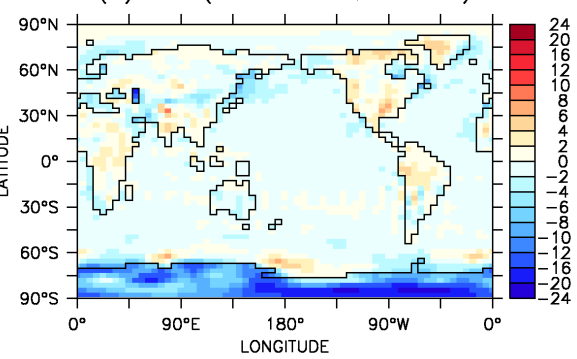

(f) JJA (Mk3L minus NCEP2)

Fig. 4. Surface air temperature $\left({ }^{\circ} \mathrm{C}\right)$, for Mk3L (average for years 201-1200) and NCEP2 (1979-2003 average): (a, c, e) Mk3L, annual, DJF and JJA means, respectively, and (b, d, f) Mk3L minus NCEP2, annual, DJF and JJA means, respectively.

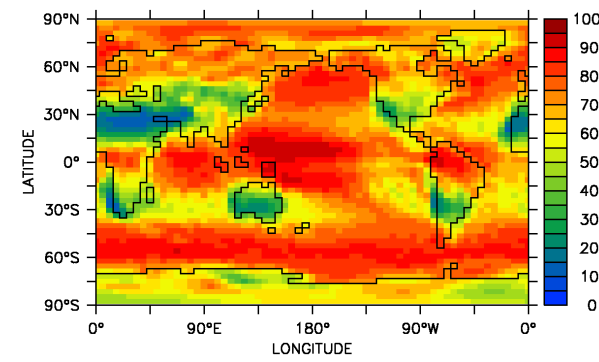

(a) $M k 3 \mathrm{~L}$

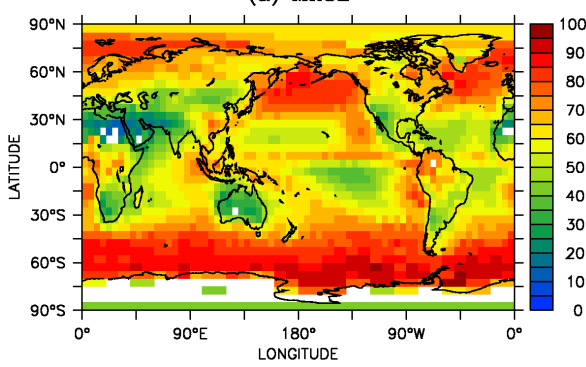

(b) Warren

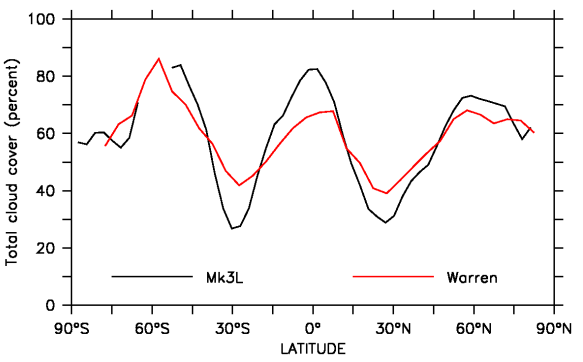

(c) Land

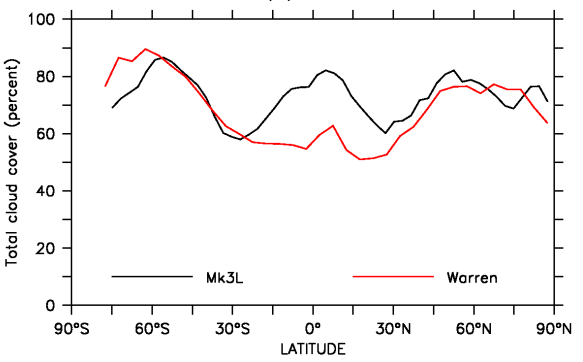

(d) Ocean

Fig. 5. Annual-mean total cloud cover (percent): (a) Mk3L (average for years 201-1200), (b) Warren climatology, (c) zonal mean over land, and (d) zonal mean over the ocean. 


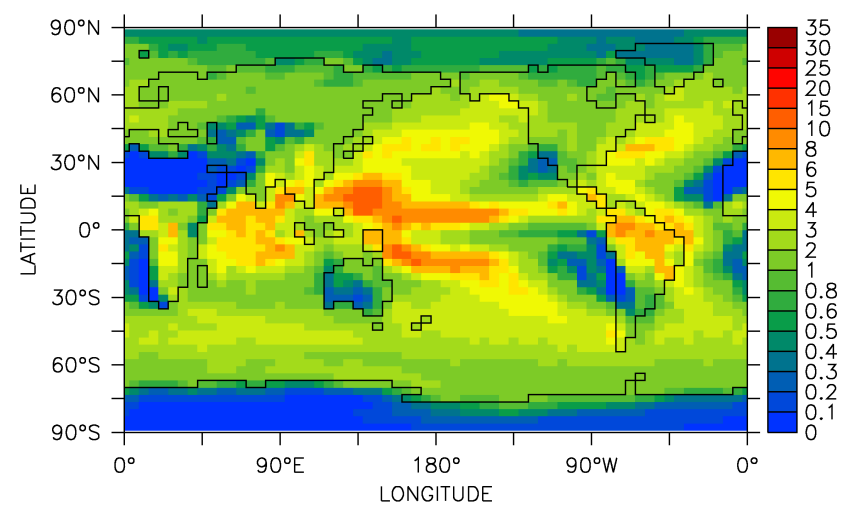

(a) Mk3L

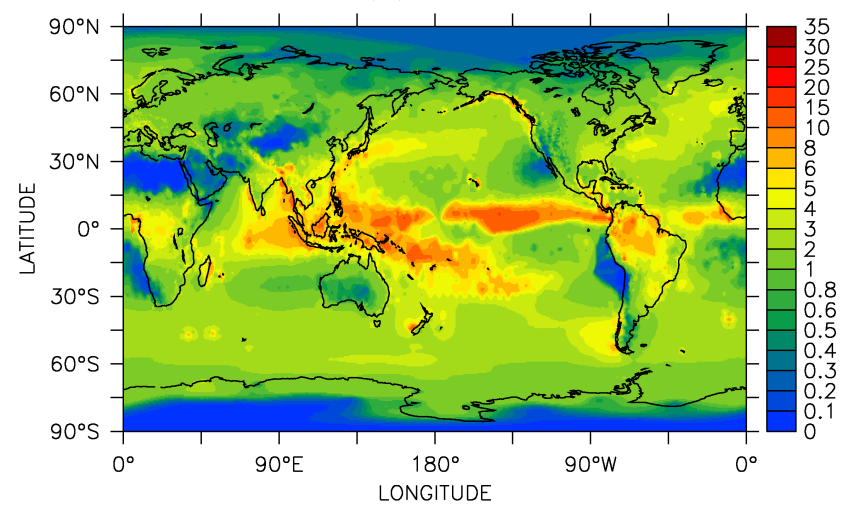

(b) Legates and Willmott v2.01

Fig. 6. Annual-mean precipitation (mm/day): (a) $\mathrm{Mk} 3 \mathrm{~L}$ (average for years 201-1200), and (b) Legates and Willmott climatology v2.01.

the Western Pacific Ocean. The model also fails to reproduce the marine stratocumulus which is encountered in the northeastern and south-eastern Pacific Ocean, and in the southeastern Atlantic Ocean. These clouds are often poorly simulated by climate models and yet, through reflection of sunlight, have a strong influence on the surface heat fluxes in these regions (Terray, 1998; Bretherton et al., 2004).

The global-mean cloud cover, and the means over land and over the ocean, are shown in Table 6. The model is in good agreement with the observed climatology over land, but the excess in the simulated cloud cover over the ocean is apparent.

\subsubsection{Precipitation}

Annual-mean precipitation is shown in Fig. 6 for $\mathrm{Mk} 3 \mathrm{~L}$ and version 2.01 of the observed climatology of Legates and Willmott (1990). The model is able to reproduce the large-scale features of the global distribution of precipitation, including the monsoonal precipitation associated with the South Pacific Convergence Zone.
Table 7. Annual-mean heat fluxes $\left(\mathrm{W} \mathrm{m}^{-2}\right.$, positive downward) at the top of the atmosphere, for Mk3L (average for years 201-1200) and ERBE (1985-1990 average).

\begin{tabular}{|c|c|c|}
\hline Flux & $\mathrm{Mk} 3 \mathrm{~L}$ & ERBE \\
\hline \multicolumn{3}{|c|}{ Outgoing shortwave radiation $\left(60^{\circ} \mathrm{S}-60^{\circ} \mathrm{N}\right)$} \\
\hline Net & -102.14 & -100.20 \\
\hline Clear sky & -51.78 & -49.81 \\
\hline Cloud forcing & -50.36 & -50.41 \\
\hline \multicolumn{3}{|c|}{ Outgoing longwave radiation $\left(60^{\circ} \mathrm{S}-60^{\circ} \mathrm{N}\right)$} \\
\hline Net & -246.31 & -242.90 \\
\hline Clear sky & -279.49 & -274.30 \\
\hline Cloud forcing & +33.18 & +31.39 \\
\hline
\end{tabular}

However, there are some regional-scale biases. Over the Western Tropical Pacific and Indian Oceans, where the simulated cloud cover is excessive, the simulated precipitation is also excessive. Over the Eastern Tropical Pacific, Indian and Atlantic Oceans, however, the simulated precipitation is deficient. The model is also too dry over the Indonesian archipelago and Central and Southwestern Australia.

\subsubsection{Atmospheric temperature and winds}

Figure 7 shows the zonal means of the simulated annualmean atmospheric temperature and zonal wind speed, and compares them with NCEP2.

The model simulates the vertical distribution of temperature well, with both the temperature and height of the minimum at the tropical tropopause being correctly simulated. However, there is a cool bias throughout the troposphere, and a warm bias throughout the stratosphere. These biases are most pronounced over Antarctica, where the troposphere is up to $8.9 \mathrm{~K}$ too cool and the stratosphere up to $5.4 \mathrm{~K}$ too warm. In the tropics, the biases in the simulated vertical profile of temperature do not exceed $3.7 \mathrm{~K}$ in magnitude.

Records derived from radiosondes and satellite-borne microwave sounders indicate cooling of the stratosphere between 1958 and 2004 of $\sim 1.5 \mathrm{~K}$, accompanied by a warming of the troposphere of less than $0.5 \mathrm{~K}$ (Trenberth et al., 2007). This suggests that the warm bias in the simulated stratosphere is largely due to the use of pre-industrial greenhouse gas concentrations in the model, while the cool bias in the simulated troposphere is largely due to deficiencies in the model physics.

The model also simulates the features of the zonal-mean circulation well, including both the strengths and positions of the atmospheric jets, and the net westerly winds in the tropical stratosphere. In the Southern Hemisphere, however, the cores of both the subtropical and polar jets are located slightly too far to the north. 


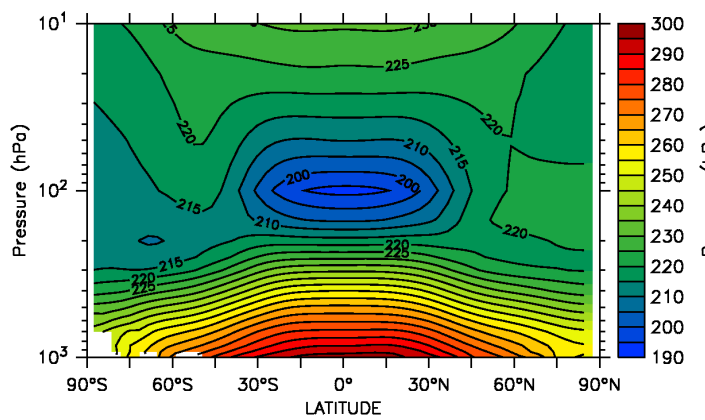

(a) Temperature (Mk3L)

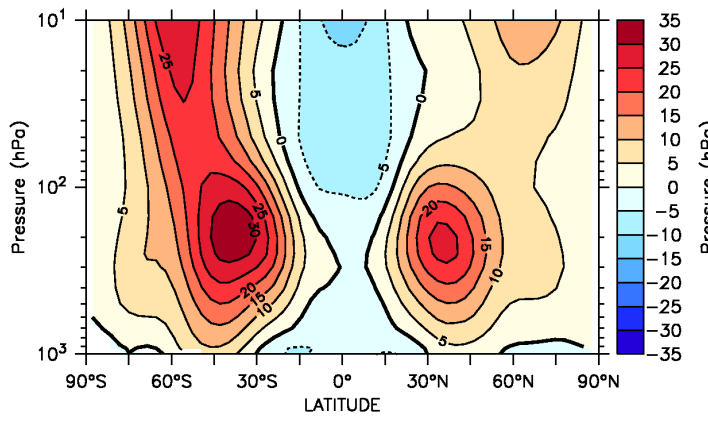

(c) Zonal wind (Mk3L)

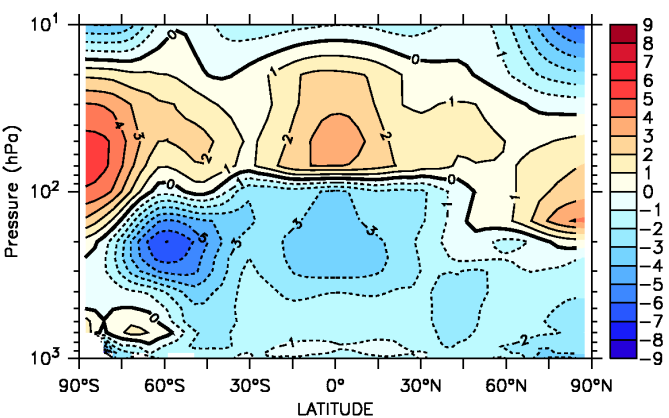

(b) Temperature (Mk3L minus NCEP2)

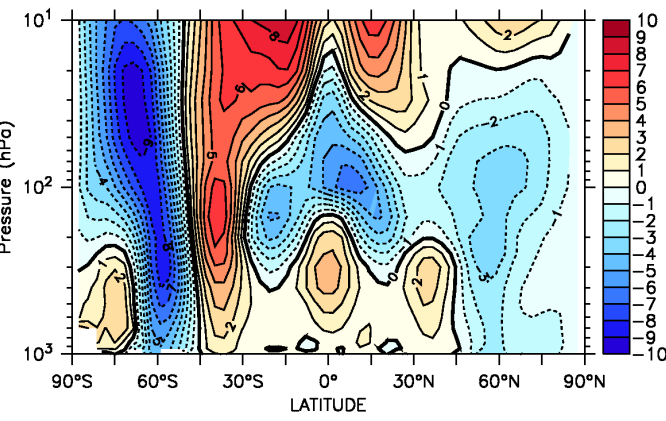

(d) Zonal wind (Mk3L minus NCEP2)

Fig. 7. The zonal means of annual-mean temperature $(\mathrm{K})$ and annual-mean zonal wind speed $\left(\mathrm{m} \mathrm{s}^{-1}\right)$ : (a, c) Mk3L (average for years $201-$ 1200), temperature and zonal wind speed, respectively, and (b, d) Mk3L minus NCEP2, temperature and zonal wind speed, respectively.

\subsubsection{Radiation}

Figure 8a shows the zonal means of the annual-mean fluxes of shortwave and longwave radiation at the top of the atmosphere, for Mk3L and ERBE (the Earth Radiation Budget Experiment; Barkstrom, 1984). The model can be seen to simulate the zonal distribution of the radiative fluxes very well.

The zonal means of the annual-mean shortwave and longwave cloud forcing are shown in Fig. 8b. The simulated longwave cloud forcing is in good agreement with observations at all latitudes. There are discrepancies in the simulated shortwave cloud forcing at high latitudes, although it should be noted that the ERBE dataset is potentially unreliable over sea ice (Lubin et al., 1998).

Table 7 shows the annual-mean fluxes of outgoing shortwave and longwave radiation at the top of the atmosphere. Because of the potential biases in the ERBE dataset at high latitudes, the comparison is restricted to the region $60^{\circ} \mathrm{S}-$ $60^{\circ} \mathrm{N}$. The model slightly overestimates the magnitudes of both the net outgoing fluxes of shortwave and longwave radiation at the top of the atmosphere. The excess of outgoing longwave radiation is due to deficient longwave absorption under clear-sky conditions. This is likely related, at least in part, to the use in the model of an atmospheric $\mathrm{CO}_{2}$ concentration appropriate for pre-industrial conditions. The magnitude of the simulated shortwave cloud forcing is in excellent agreement with observations, while the model slightly overestimates the longwave cloud forcing.

\subsection{Sea ice}

The simulated seasonal cycles in the Northern and Southern Hemisphere sea ice extents and volumes are plotted in Fig. 9. Sea ice extents derived from the NOAA Optimum Interpolation (OI) sea surface temperature analysis v2 (Reynolds et al., 2002) are also shown; this analysis combines satellite observations with in situ observations from ships and buoys. The conventional definition of sea ice extent (e.g., Parkinson et al., 1999) is employed, namely that the sea ice extent is defined as the area over which the ice concentration is greater than or equal to $15 \%$.

The simulated annual cycle in ice extent is well simulated in both hemispheres. However, too much ice persists through the summer in the Northern Hemisphere, while too much ice forms in winter in the Southern Hemisphere. The simulated annual-mean sea ice extents in the Northern and Southern Hemispheres are $12.8 \times 10^{12} \mathrm{~m}^{2}$ and $13.6 \times 10^{12} \mathrm{~m}^{2}$, respectively. These values are in good agreement with the observed extents of $12.2 \times 10^{12} \mathrm{~m}^{2}$ and $13.2 \times 10^{12} \mathrm{~m}^{2}$, respectively.

Figures 10 and 11 compare the simulated March and September ice concentrations, for the Northern and Southern Hemispheres, respectively, with those derived from the NOAA OI analysis v2. In the Northern Hemisphere, the extent of sea ice cover in March is in good agreement with 


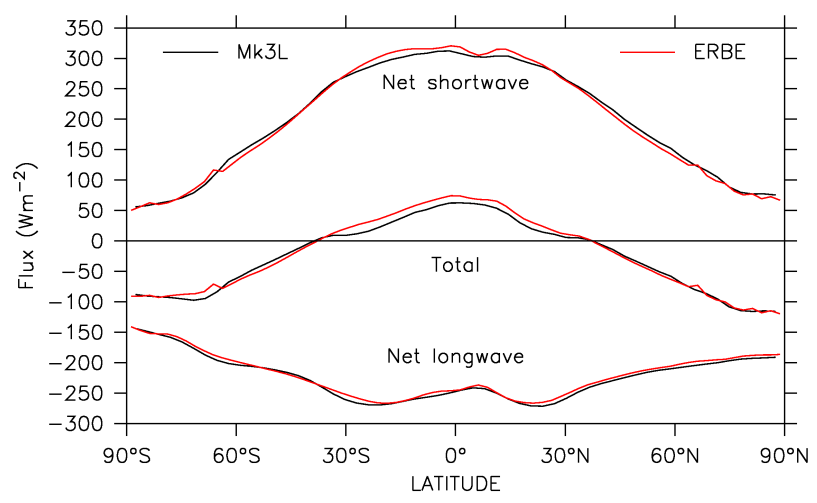

(a) Top-of-atmosphere radiation

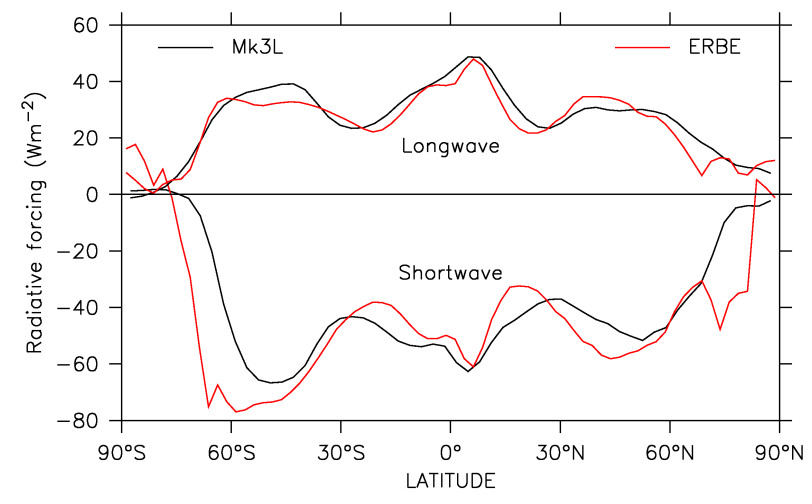

(b) Cloud forcing

Fig. 8. The zonal means of the annual-mean heat fluxes (positive downward) at the top of the atmosphere for Mk3L (black, average for years 201-1200) and ERBE (red, 1985-1990 average): (a) net shortwave, net longwave and total radiation, and (b) shortwave and longwave cloud forcing.

observations. However, the ice concentration is too low in Hudson Bay. In September, although the extent of the sea ice cover in the Arctic Ocean is again in good agreement with observations, the ice in Hudson Bay fails to melt. It is this deficiency that accounts for the excessive Northern Hemisphere sea ice extent in summer.

In the Southern Hemisphere, the extent of the sea ice cover is in reasonable agreement with observations. However, in September the ice cover extends slightly too far out from the coast at most longitudes, accounting for the excessive hemispheric sea ice extent in winter. The ice concentrations are also too low in both the Weddell and Ross Seas, with the result that too little ice persists in these seas through the summer.

The simulated March and September sea ice thicknesses are shown in Fig. 12. Observational datasets of ice thickness are limited in both spatial and temporal coverage. However, Wadhams (2000), summarising the available data, indicates that ice thicknesses in the Arctic range from $\sim 1 \mathrm{~m}$ in the sub-polar regions, such as Baffin Bay and the Southern Greenland Sea, to $\sim 7-8 \mathrm{~m}$ along the northern coasts of

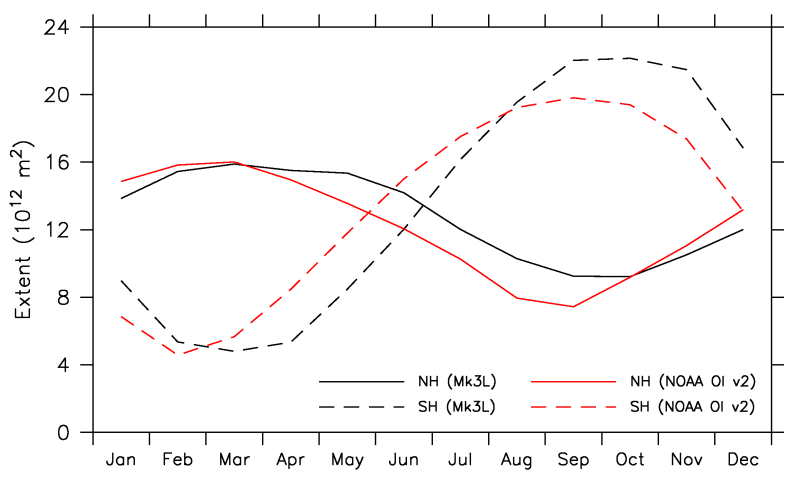

(a) Sea ice extent

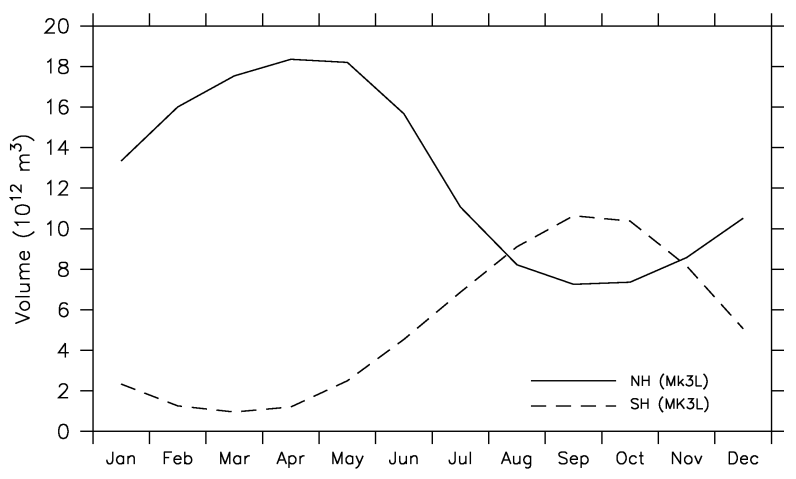

(b) Sea ice volume

Fig. 9. Sea ice extent $\left(10^{12} \mathrm{~m}^{2}\right)$ and volume $\left(10^{12} \mathrm{~m}^{3}\right)$ : (a) sea ice extent for Mk3L (black, average for years 201-1200) and the NOAA OI analysis v2 (red, 1982-2003 average), and (b) sea ice volume for Mk3L.

Greenland and the Canadian archipelago. In Hudson Bay, the model forms excessively thick ice that persists throughout the year. As the ice concentration here is too low in winter, the model therefore appears to grow ice preferentially downwards, rather than outwards, in this region. However, the sea ice that forms elsewhere is much thinner. Compared to observational estimates, the simulated Arctic sea ice cover is therefore generally too thin.

Worby et al. (2008), combining data from 83 ship voyages and 2 helicopter flights for the period 1980-2005, derive mean summer and winter sea ice thicknesses for the Antarctic of $1.17 \pm 1.12 \mathrm{~m}$ and $0.66 \pm 0.60 \mathrm{~m}$, respectively. Compared to these estimates, the simulated Antarctic sea ice thickness is reasonable in winter, but too thin in summer. This suggests that the model underestimates the proportion of multi-year ice. As the ice extent is too great in winter, this indicates a preference to grow ice outwards, rather than downwards, in the Southern Ocean. 


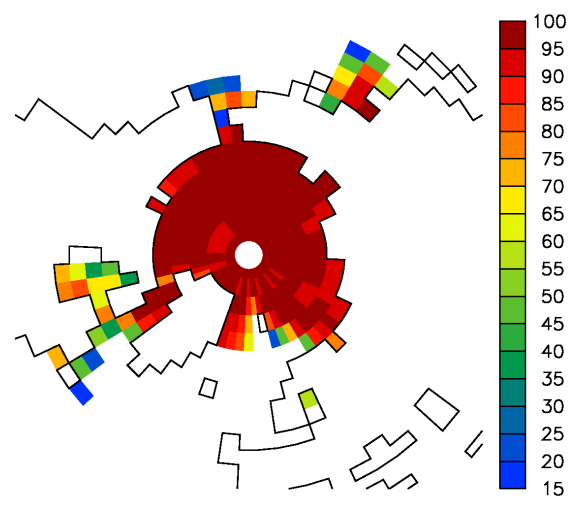

(a) Mk3L (March)

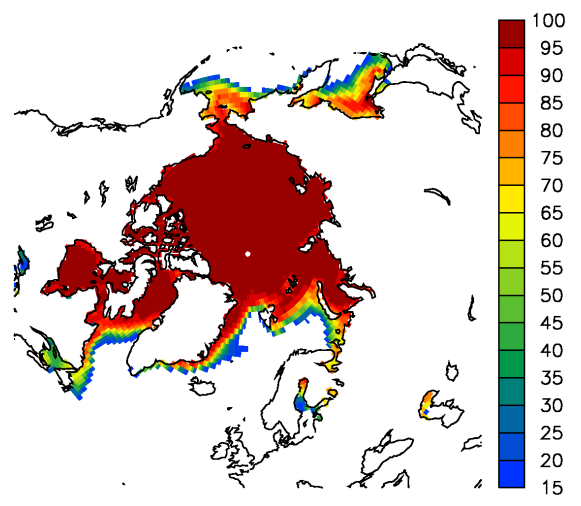

(c) NOAA OI v2 (March)

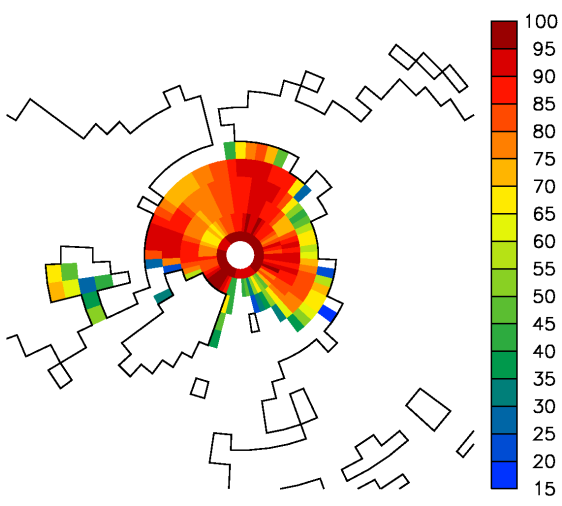

(b) Mk3L (September)

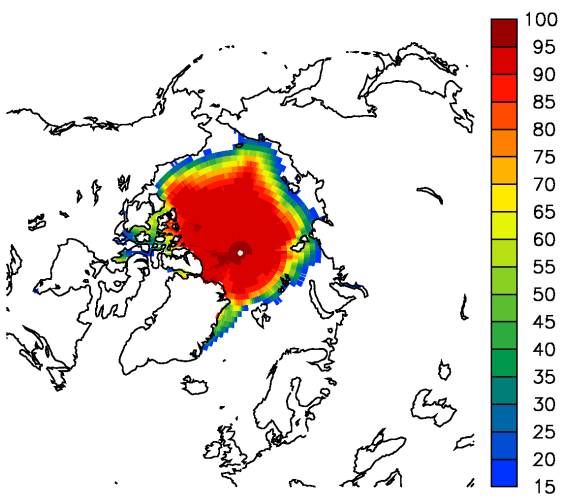

(d) NOAA OI v2 (September)

Fig. 10. Northern Hemisphere sea ice concentration (percent): (a, b) Mk3L (average for years 201-1200), March and September, respectively, and (c, d), the NOAA OI analysis v2 (1982-2003 average), March and September, respectively. Values are only shown where the concentration is greater than or equal to $15 \%$.

\subsection{Ocean}

\subsubsection{Water properties}

The vertical profiles of potential temperature and salinity are shown in Fig. 13, for both Mk3L and the World Ocean Atlas 1998. The potential temperature represents the temperature that a volume of seawater would have if raised adiabatically to the surface. While the model prognoses the potential temperature, the World Ocean Atlas 1998 dataset contains in situ temperatures. These are therefore converted to potential temperature, using the multivariant polynomial method of Bryden (1973).

The model ocean is too warm above $1400 \mathrm{~m}$, but too cold at depth. It also has a consistent fresh bias, with the magnitude of the model discrepancy increasing with depth. Taking the average over the bottom five model levels, which span the depth range $2350-4600 \mathrm{~m}$, the model is too cold by $1.09 \mathrm{~K}$ and too fresh by $0.27 \mathrm{psu}$.
Figure 14 shows the simulated zonal-mean potential temperature and salinity, and compares them with the World Ocean Atlas 1998. The model is too warm in the Arctic Ocean, and in the tropical and mid-latitude upper ocean. In contrast, it is too cold in the Southern Ocean and at depth. The simulated zonal-mean salinity exhibits a modest negative bias at most latitudes and depths. A slight positive bias in the upper ocean in the Southern Hemisphere arises from the failure by the model to adequately simulate the formation of Antarctic Intermediate Water.

The cold and fresh bias of the deep ocean is consistent with the biases exhibited by other ocean models with comparable physics and spatial resolutions (e.g., Moore and Reason, 1993; England and Hirst, 1997; Hirst et al., 2000; Bi, 2002). These deficiencies in the simulated climate can be attributed, at least in part, to the use of the relaxation surface boundary condition, as a result of which the model is unable to adequately simulate the peak winter density and salinity of high-latitude surface waters (Phipps, 2006b). 


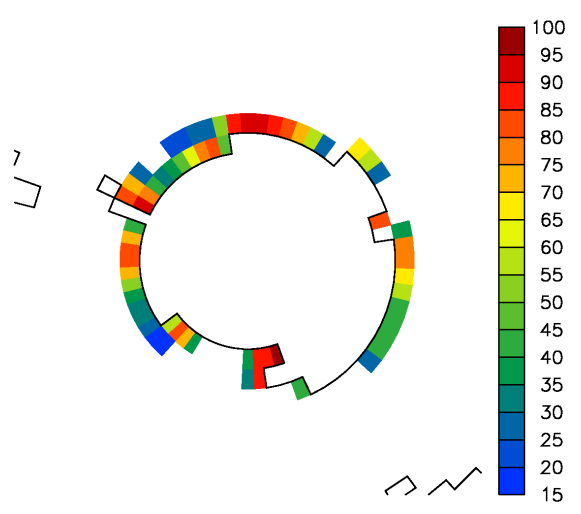

(a) Mk3L (March)

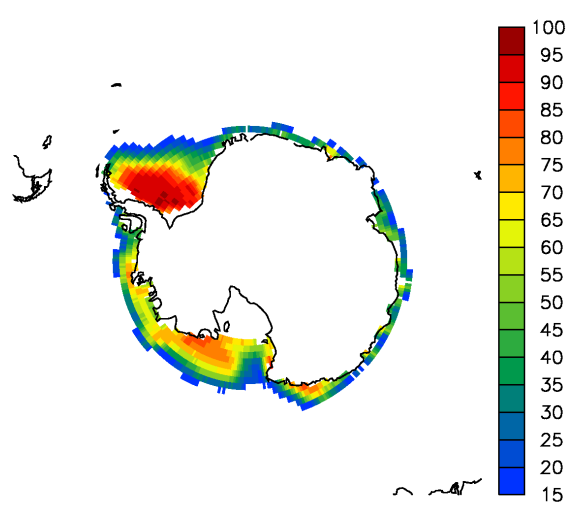

(c) NOAA OI v2 (March)

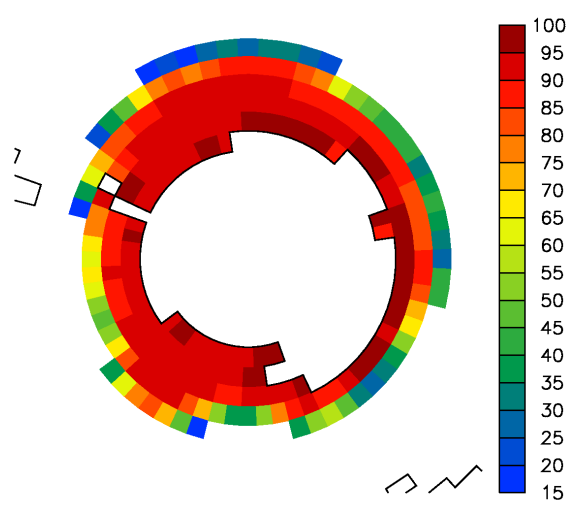

(b) Mk3L (September)

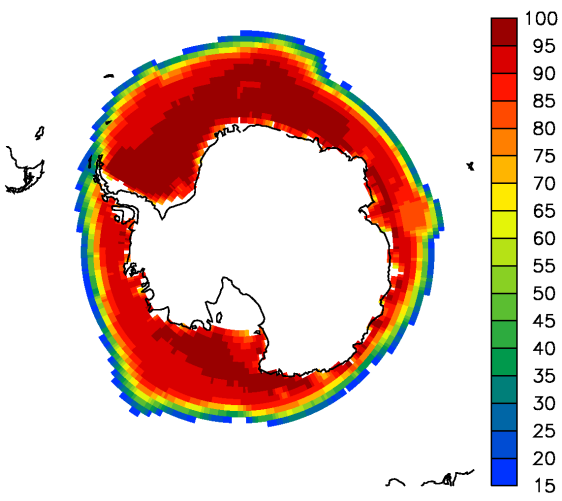

(d) NOAA OI v2 (September)

Fig. 11. Southern Hemisphere sea ice concentration (percent): (a, b) Mk3L (average for years 201-1200), March and September, respectively, and (c, d), the NOAA OI v2 (1982-2003 average), March and September, respectively. Values are only shown where the concentration is greater than or equal to $15 \%$.

\subsubsection{Thermohaline circulation}

The meridional overturning streamfunctions for the world ocean, and for the Atlantic and Pacific/Indian Oceans, are shown in Fig. 15; the rate of overturning is calculated by integrating both the large-scale and eddy-induced transport components. The rates of formation of North Atlantic Deep Water (NADW) and Antarctic Bottom Water (AABW) are $14.7 \mathrm{~Sv}$ and $11.8 \mathrm{~Sv}$, respectively.

Observationally-based estimates of the rate of NADW formation lie within the range 15-20 Sv (Gordon, 1986), while those for the rate of $\mathrm{AABW}$ formation lie within the range 5-15 Sv (e.g., Gill, 1973; Carmack, 1977). The observed distribution of dissolved chlorofluorocarbons has also been used to produce estimated rates of NADW and AABW formation of $\sim 17.2 \mathrm{~Sv}$ (Smethie and Fine, 2001) and $\sim 8.1-$ 9.4 Sv (Orsi et al., 1999), respectively. The simulated rate of NADW formation is therefore slightly too weak, while the rate of $\mathrm{AABW}$ formation may be too strong.
Similar biases in the simulated rate of NADW formation are encountered in other ocean models with comparable physics and spatial resolutions (e.g., England and Hirst, 1997; Hirst et al., 2000; Bi, 2002). As AABW is $\sim 2 \mathrm{~K}$ colder than NADW (Orsi et al., 2001), the biases in the rate of deep water formation provide a possible explanation for the cold bias in the simulated deep ocean. This hypothesis is consistent with the fact that the cold bias arises from those regions of the world ocean that are ventilated by AABW (Fig. 14b).

\subsubsection{Barotropic circulation}

The annual-mean barotropic streamfunction is shown in Fig. 16. The Antarctic Circumpolar Current is evident, as are the mid-latitude gyres in the Atlantic, Pacific and Indian Oceans.

The simulated rate of transport through Drake Passage is $147 \mathrm{~Sv}$, which agrees well with observational estimates. Cunningham et al. (2003), using the data from six hydrographic sections conducted across Drake Passage between 1993 and 2000 as part of the World Ocean Circulation Experiment 

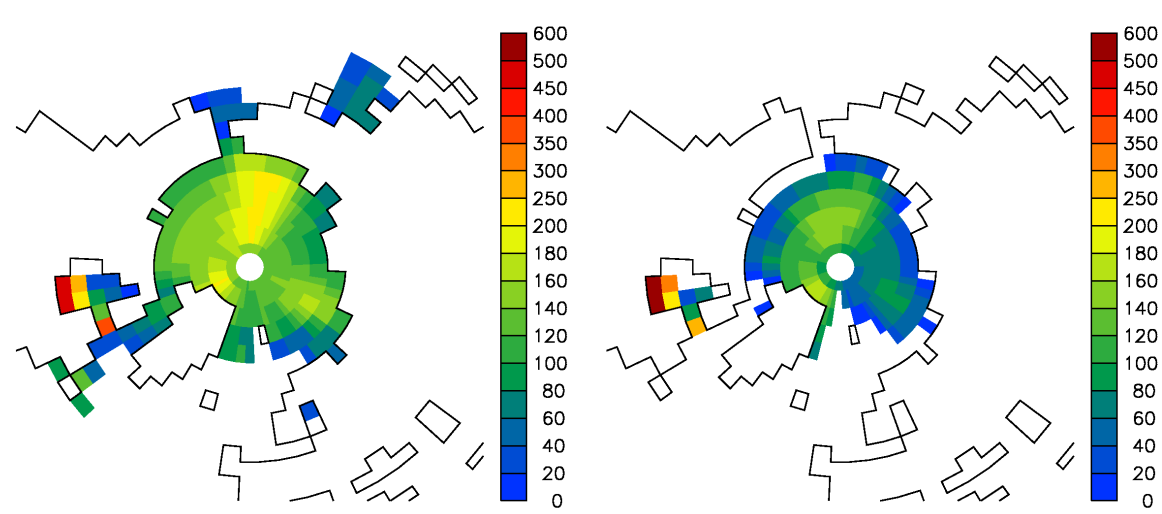

(a) Northern Hemisphere (March)

(b) Northern Hemisphere (September)

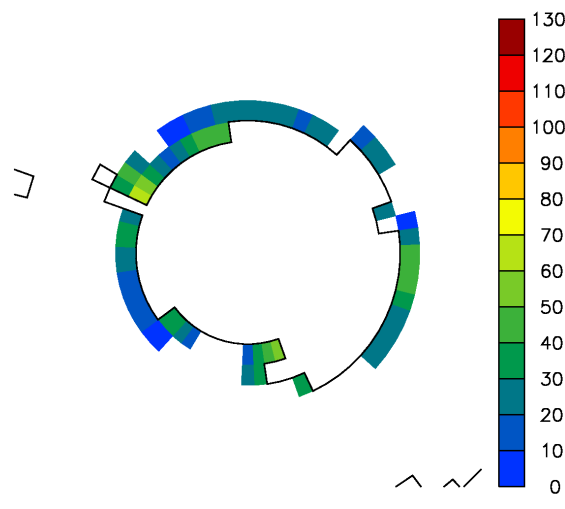

(c) Southern Hemisphere (March)

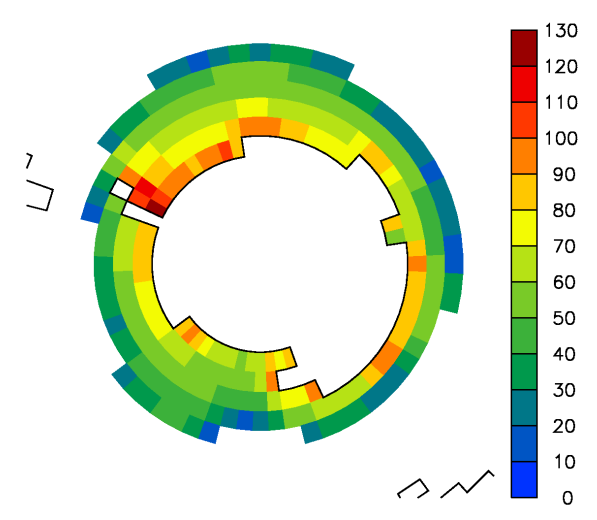

(d) Southern Hemisphere (September)

Fig. 12. Sea ice thicknesses for Mk3L (average for years 201-1200, cm): (a, b) Northern Hemisphere, March and September, respectively, and (c, d) Southern Hemisphere, March and September, respectively. The values shown are the mean thickness of sea ice where present, and are not weighted by the concentration. Values are only shown where the concentration is greater than or equal to $15 \%$.

(WOCE), estimate that the rate of transport is $136.7 \pm 7.8 \mathrm{~Sv}$. Stammer et al. (2003), using an ocean global circulation model to assimilate WOCE data over the same period, estimate that the rate of transport through Drake Passage is $124 \pm 5 \mathrm{~Sv}$. The agreement between Mk3L and observations is particularly good when it is considered that other global ocean models simulate rates of transport through Drake Passage which range from less than $100 \mathrm{~Sv}$ to more than $200 \mathrm{~Sv}$ (Olbers et al., 2004).

The simulated western boundary currents, however, are too weak and too diffuse. The maximum strength of the simulated Gulf Stream, for example, is $24.4 \mathrm{~Sv}$, whereas the observed strength is $\sim 30.5 \mathrm{~Sv}$ (Schott et al., 1988). This problem is encountered in coarse-resolution ocean models (e.g., Moore and Reason, 1993; Bi, 2002), and arises from the large horizontal viscosity which is required to ensure resolution of viscous boundary layers at the lateral walls (Bryan et al., 1975). For the configuration of the model analysed herein, the horizontal viscosity was set to $9 \times 10^{5} \mathrm{~m}^{2} \mathrm{~s}^{-1}$.

\section{Climate variability}

In this section, the internal variability within the control simulation is analysed, and the simulated climate variability is evaluated against observational and reanalysis datasets. Analogously to the evaluation of the mean climate (Sect. 5), discrepancies may arise because of differences between the characteristics of modern natural climate variability and the natural climate variability that prevailed during the preindustrial era.

Mk3L employs flux adjustments to improve the realism of the simulated climate. Flux adjustments influence the internal variability within climate models, both via their influence on the mean state and via their influence on the coupling between the atmosphere and the ocean (e.g. Kitoh et al., 2007). Although the flux adjustments applied within Mk3L consist of a fixed annual cycle, it is nonetheless possible that they determine the structure of the simulated climate variability (Weaver and Hughes, 1996). In other models, it has been shown that flux adjustments can influence the characteristics 


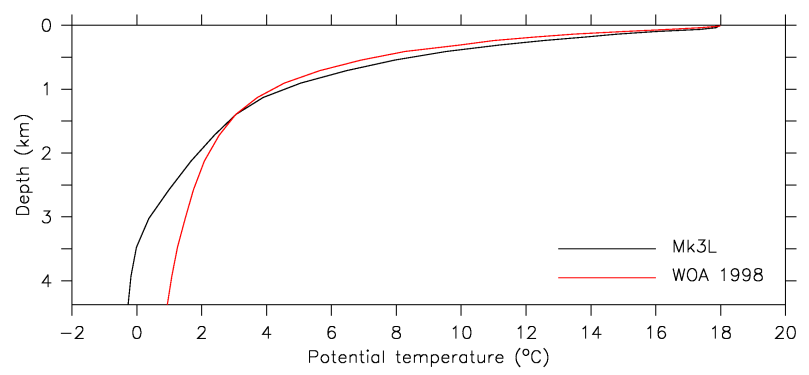

(a) Potential temperature

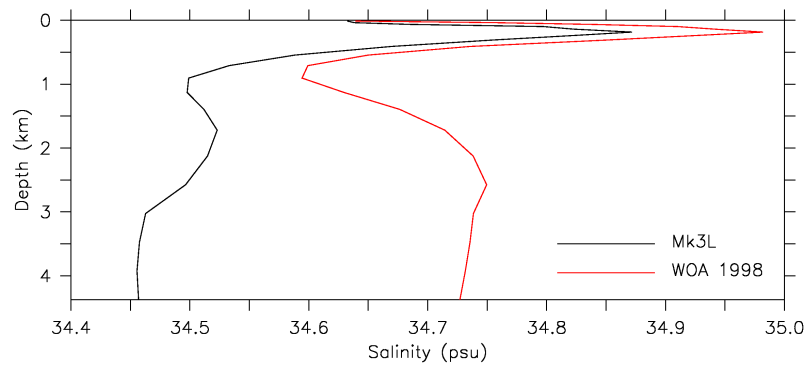

(b) Salinity

Fig. 13. The zonal- and meridional-mean potential temperature and salinity for Mk3L (black, average for years 201-1200), and the World Ocean Atlas 1998 (red): (a) potential temperature, and (b) salinity.

of the simulated present-day El Niño-Southern Oscillation, as well as the response to changes in the seasonal cycle of insolation (Kitoh et al., 2007; Brown et al., 2008). While a full analysis of the role of flux adjustments within Mk3L is beyond the scope of this paper, it is important to bear these caveats in mind when evaluating the simulated climate variability.

\subsection{Tropics}

Figure 17 shows the leading principal component (PC) of the monthly sea surface temperature anomalies within the region $45^{\circ} \mathrm{S}-45^{\circ} \mathrm{N}$, for Mk3L and for the HadISST1 observational analysis (Rayner et al., 2003).

In both the model and the analysis, El Niño-Southern Oscillation (ENSO; Philander, 1990) is the leading mode of variability in tropical sea surface temperatures. While the model successfully captures the overall spatial structure of the SST anomalies associated with ENSO, the location of greatest SST variability is located too far to the west. In the model, the largest anomalies in the equatorial Pacific Ocean occur at $163^{\circ} \mathrm{W}$ whereas, in the analysis, they occur at $113^{\circ} \mathrm{W}$.

The simulated ENSO variability is also too weak. In the model, the standard deviations of the monthly SST anomalies in the Niño $3.4\left(170^{\circ}-120^{\circ} \mathrm{W}, 5^{\circ} \mathrm{S}-5^{\circ} \mathrm{N}\right)$ and Niño 3 $\left(150^{\circ}-90^{\circ} \mathrm{W}, 5^{\circ} \mathrm{S}-5^{\circ} \mathrm{N}\right)$ regions are $0.51 \mathrm{~K}$ and $0.40 \mathrm{~K}$, respectively. In contrast, the standard deviations for the period
1871-2003 according to the HadISST1 analysis are $0.76 \mathrm{~K}$ and $0.79 \mathrm{~K}$, respectively. Thus the amplitude of the simulated ENSO variability is $33 \%$ weaker than the observed variability in the Niño 3.4 region, and $50 \%$ weaker than the observed variability in the Niño 3 region. As the region of greatest SST variability is located too far to the west in the model, the simulated variability is particularly deficient in the Niño 3 region.

The wavelet power spectra of the Niño 3.4 SST anomaly, for both the model and for HadISST1, are shown in Fig. 18. Wavelet spectra were calculated using the method of Torrence and Compo (1998), modified following Liu et al. (2007) to ensure a physically consistent definition of energy. The observed power spectrum has peak variability at $3.6 \mathrm{yr}$, with a weak secondary maximum at $13.1 \mathrm{yr}$. The simulated power spectrum, however, has peak variability at $6.0 \mathrm{yr}$, with a secondary maximum of almost equal magnitude at $20.2 \mathrm{yr}$. The simulated ENSO has less power than observations at periods shorter than $6 \mathrm{yr}$, and more power than observations on interdecadal timescales.

Within Mk3L, the simulated ENSO is therefore too weak, too slow, and characterised by excessive modulation on interdecadal timescales. The region of greatest SST variability is also located too far to the west. Such failings are typical of low-resolution coupled climate system models, such as those which participated in the Coupled Model Intercomparison Project (AchutaRao and Sperber, 2002). Higher-resolution models, such as those which contributed to the IPCC Fourth Assessment Report, are able to simulate ENSO variability more realistically (Guilyardi, 2006; Guilyardi et al., 2009). The deficiencies in the simulated ENSO variability within $\mathrm{Mk} 3 \mathrm{~L}$ are therefore likely to be a consequence of the reduced spatial resolution.

\subsection{Extratropics}

Figure 19a,b shows the leading principal component of the monthly $500 \mathrm{hPa}$ geopotential height anomalies for the Northern Hemisphere extratropics, defined here as the region $20^{\circ}-90^{\circ} \mathrm{N}$, for $\mathrm{Mk} 3 \mathrm{~L}$ and for NCEP2. The Northern Annular Mode (NAM, also known as the Arctic Oscillation; Thompson and Wallace, 1998, 2000) is the leading mode of variability in both the model and the analysis, with PC1 (PC2) explaining $13.3 \%(10.4 \%)$ and $14.2 \%(9.7 \%)$ of the variance in Mk3L and NCEP2, respectively. The model captures the zonally-symmetric nature of the NAM, with negative geopotential height anomalies in the polar region surrounded by positive anomalies at mid-latitudes. However, the largest negative anomaly is located over Alaska in the model, whereas it occurs over the North Atlantic in the reanalyis. In the Atlantic sector, the simulated variability therefore consists of a north-sorth dipole, in contrast to the more tripolar structure seen in the reanalysis. Over the Pacific Ocean, the simulated variability is too weak, with the maximum geopotential height anomaly located too far to the south and west. 


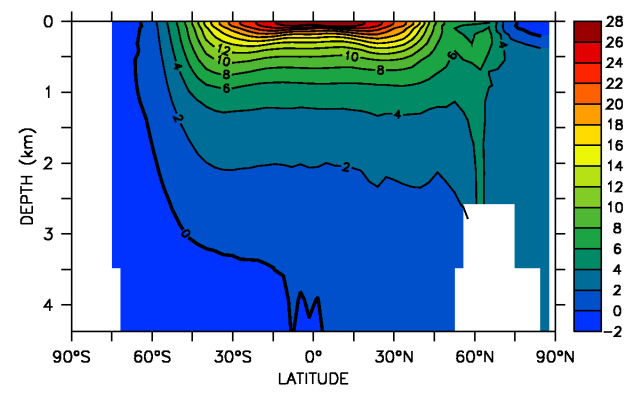

(a) Temperature (Mk3L)

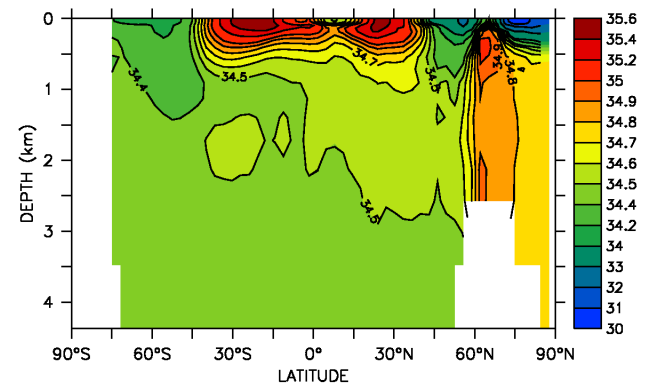

(c) Salinity (Mk3L)

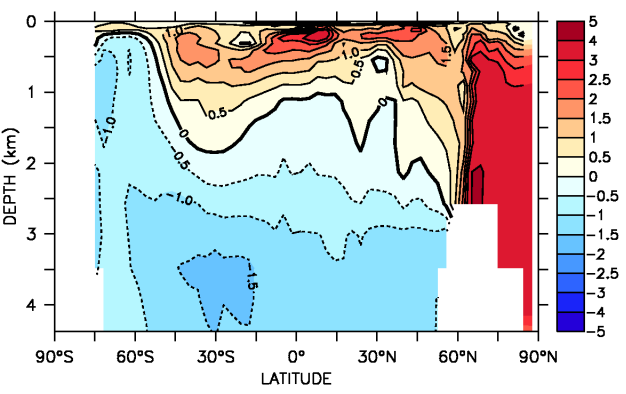

(b) Temperature (Mk3L-WOA1998)

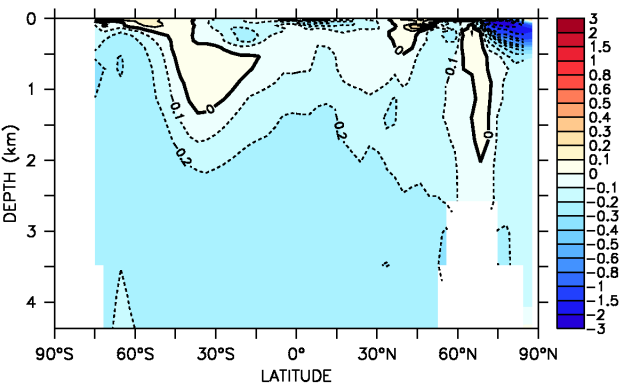

(d) Salinity (Mk3L-WOA1998)

Fig. 14. The zonal-mean potential temperature $\left({ }^{\circ} \mathrm{C}\right.$ ) and salinity (psu) for the world ocean: (a, c) Mk3L (average for years 201-1200), and (b, d) Mk3L minus the World Ocean Atlas 1998.

Figure 19c,d shows the leading principal component of the monthly $500 \mathrm{hPa}$ geopotential height anomalies for the Southern Hemisphere extratropics, defined here as the region $20^{\circ}-90^{\circ} \mathrm{S}$, for Mk3L and for NCEP2. The Southern Annular Mode (SAM, also known as the Antarctic Oscillation; Thompson and Wallace, 2000; Marshall, 2003) is the leading mode of variability in both the model and the analysis, with PC1 (PC2) explaining 23.4\% (8.3\%) and $17.6 \%$ (10.8\%) of the variance in Mk3L and NCEP2, respectively. Although the model is able to capture the annular nature of the SAM, the simulated variability exhibits an excessive zonal symmetry. The largest negative geopotential height anomalies lie over Eastern Antarctica, with the model failing to resolve the dipole in variability in the Southern Pacific Ocean.

\section{Climate drift}

In a climate system model that is designed primarily for millennial-scale climate simulations, the rate of drift in the control state should be negligible. Mk3L employs fixed annual-cycle flux adjustments to minimise the rate of drift, as well as to improve the realism of the simulated climate. The adjustments are intended to prevent the mean states of the atmosphere, land surface, sea ice and ocean from drifting away from the states of the stand-alone models (Phipps, 2006b). This section examines the rate and nature of any residual drift that remains.

\subsection{Surface air temperature}

The evolution of the simulated global-mean surface air temperature (SAT) is shown in Fig. 20a. The model exhibits a slow but steady cooling trend, which becomes well established after year 1200. The global-mean SAT decreases $0.61 \mathrm{~K}$ by the end of the simulation, with the average rate of cooling being $0.015 \mathrm{~K}$ per century. There is no difference between the rates of change over land and over the ocean.

\subsection{Sea ice}

Figure 20b,c shows the evolution of the sea ice extent and volume in each hemisphere. Some initial adjustment during the first century of the simulation is apparent. In the Northern Hemisphere, this consists of the expansion of ice cover into Hudson Bay and the Labrador Sea (not shown), bringing the simulated ice cover into better agreement with observations. Thereafter, the Northern Hemisphere ice extent is relatively stable, increasing from 12.0 to $12.9 \times 10^{12} \mathrm{~m}^{2}$ between the second and final centuries. The sea ice extent in the Southern Hemisphere, however, exhibits a steady upwards trend after year 500. Between the second and final centuries of the simulation, the extent increases from 12.5 to $16.6 \times 10^{12} \mathrm{~m}^{2}$.

The sea ice volumes in each hemisphere exhibit similar behaviour to the sea ice extent. The Northern Hemisphere ice volume is relatively stable, increasing from 12.8 to $15.2 \times 10^{12} \mathrm{~m}^{3}$ between the second and final centuries of the simulation. This increase occurs at around year 1500, when the global cooling trend causes ice cover to form in 


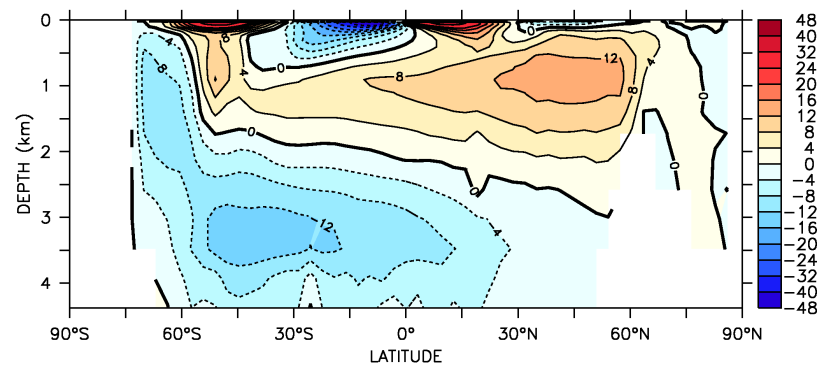

(a) World Ocean

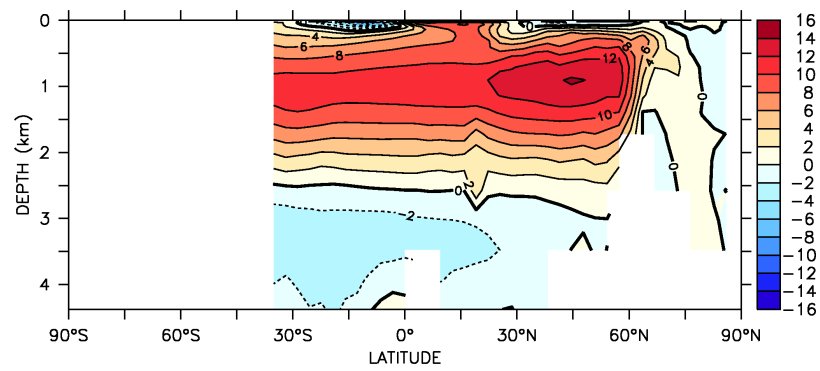

(b) Atlantic Ocean

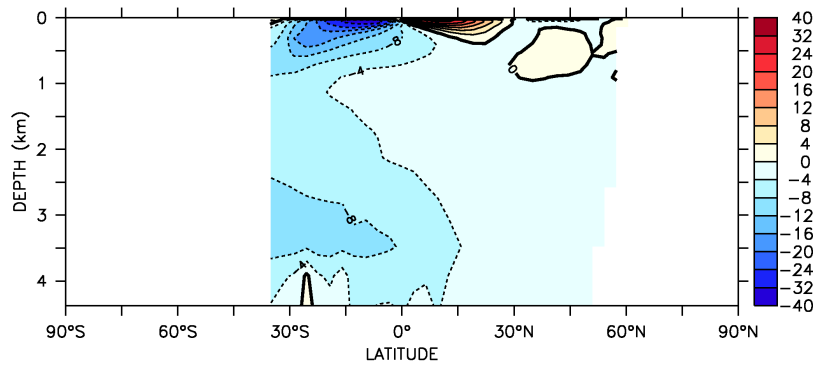

(c) Pacific/Indian Oceans

Fig. 15. Meridional overturning streamfunctions for Mk3L (average for years 201-1200, Sv): (a) the world ocean, (b) the Atlantic Ocean, and (c) the Pacific/Indian Oceans.

the Caspian Sea for the first time (not shown). The Southern Hemisphere sea ice volume exhibits a steady upwards trend after year 500 , increasing from 5.1 to $7.9 \times 10^{12} \mathrm{~m}^{3}$ between the second and final centuries.

\subsection{Sea surface temperature and salinity}

The evolutions of the simulated global-mean sea surface temperature (SST) and sea surface salinity (SSS) are shown in Fig. 21. The drift in the simulated SST is similar to that in the simulated surface air temperature, with a steady cooling trend becoming established by year 1200 . The global-mean SST decreases $0.44 \mathrm{~K}$ by the end of the simulation, with the average rate of cooling being $0.011 \mathrm{~K}$ per century. The simulated global-mean SSS exhibits a slow but steady freshening trend, decreasing 0.11 psu over the course of the simulation.

\subsection{Oceanic circulation}

Figure 22 shows the evolution in the rates of North Atlantic Deep Water (NADW) and Antarctic Bottom Water (AABW) formation, and in the rate of volume transport through Drake Passage. After some initial adjustment, the rates of deep water formation stabilise. Excluding the first century of the simulation, the mean rates of NADW and AABW formation are 14.4 and 11.9 Sv, respectively. The Antarctic Circumpolar Current (ACC), however, exhibits a slight strengthening trend, with the mean strength increasing from 146 to $160 \mathrm{~Sv}$ between the second and final centuries of the simulation. In the CSIRO Mk2 coupled model, the strength of the ACC has been shown to be sensitive to changes in the density structure of the ocean interior (Bi, 2002). Such density changes, arising from the cooling trend in the Southern Ocean, may explain the ACC trend encountered here.

\subsection{Summary}

The control climate of the Mk3L coupled climate system model exhibits a high degree of stability on millennial timescales. Over the course of a 4000-yr control simulation, the global-mean surface air temperature cools at an average rate of just $0.015 \mathrm{~K}$ per century. This cooling trend is much smaller than that exhibited by the majority of models with comparable physics and spatial resolutions (Bell et al., 2000; Lambert and Boer, 2001). The drift exhibited by Mk3L is less, typically by between one and two orders of magnitude, than that exhibited by all seven of the non-flux-adjusted models which participated in the Coupled Model Intercomparison Project (Lambert and Boer, 2001, Table 7), and by all but one of the eight models which employed flux adjustments. The only model to exhibit a smaller rate of drift was CSIRO Mk2, on which Mk3L is partly based.

The cooling trend exhibited by Mk3L is slow but consistent, and therefore respresents a source of concern. If the trends were to continue at the same rate as during the simulation presented here then, during a 10,000-yr simulation, global-mean surface air temperature would be expected to cool by $\sim 1.5 \mathrm{~K}$, Southern Hemisphere sea ice volume would be expected to increase by $\sim 140 \%$, and the Antarctic Circumpolar Current would be expected to strengthen by $\sim 25 \%$. Such rates of change would restrict the utility of the model for experiments which require very long integrations, such as the simulation of a full glacial cycle or a glacialinterglacial transition.

Further analysis of the drift (Phipps, 2006b) reveals that it is a consequence of the initial adjustment during the first century of the simulation, during which the Northern Hemisphere sea ice cover expands into Hudson Bay and the Labrador Sea. The consequent cooling in the North Atlantic results in a decrease in the temperature of North Atlantic Deep Water, which leads to a slow but ongoing cooling of the ocean. It is therefore possible that the drift could be avoided 


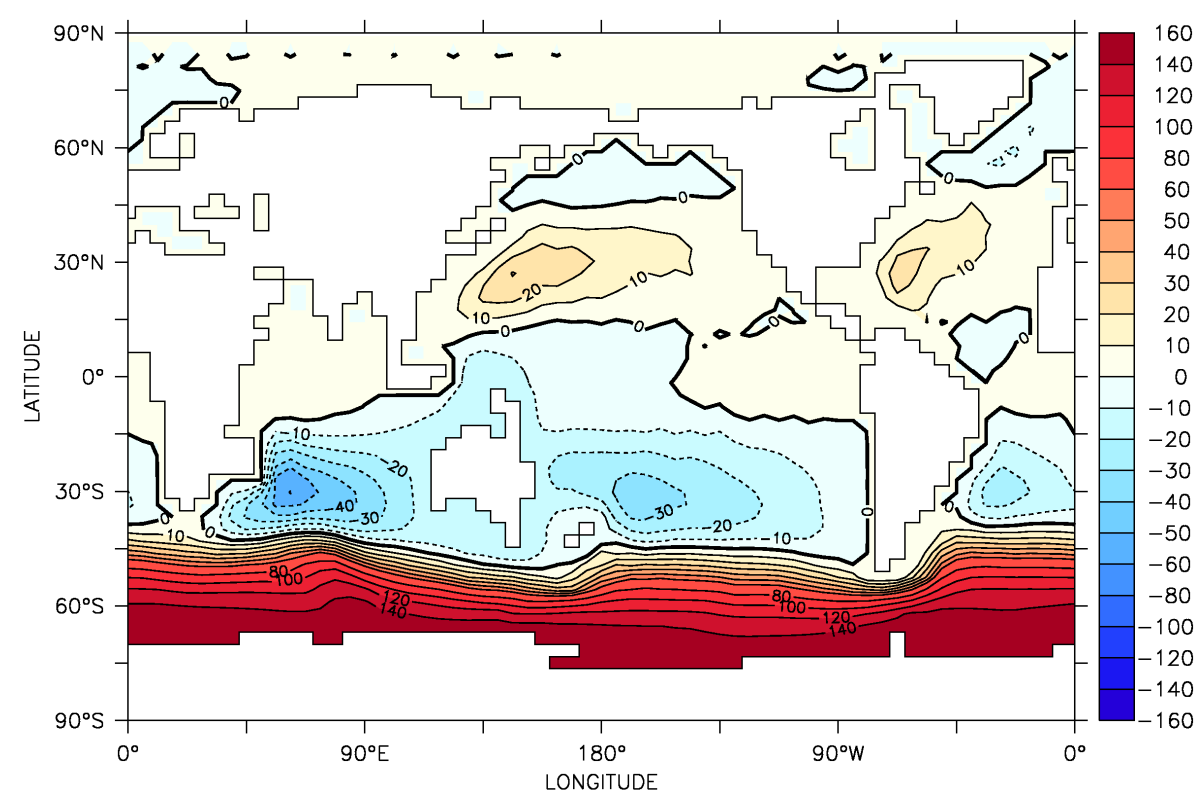

Fig. 16. The annual-mean barotropic streamfunction for Mk3L (average for years 201-1200, Sv).

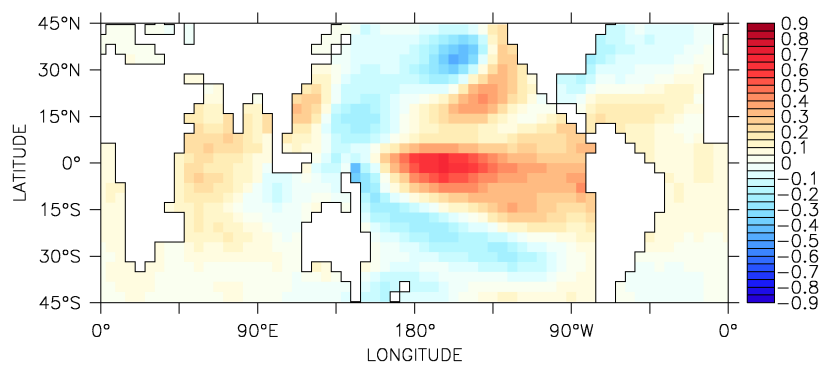

(a) Mk3L

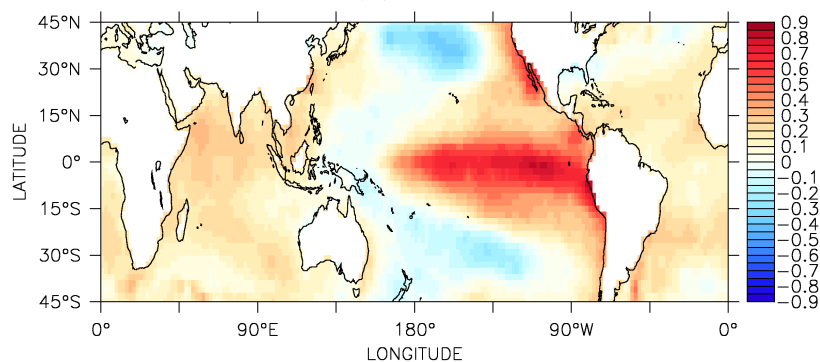

(b) HadISST1

Fig. 17. The leading principal component of the monthly sea surface temperature anomalies (K) for (a) Mk3L, years 201-1200, and (b) the HadISST1 analysis, 1871-2003.

by modifying the spin-up procedure, such that the coupled climate system model is initialised with more realistic sea ice cover.

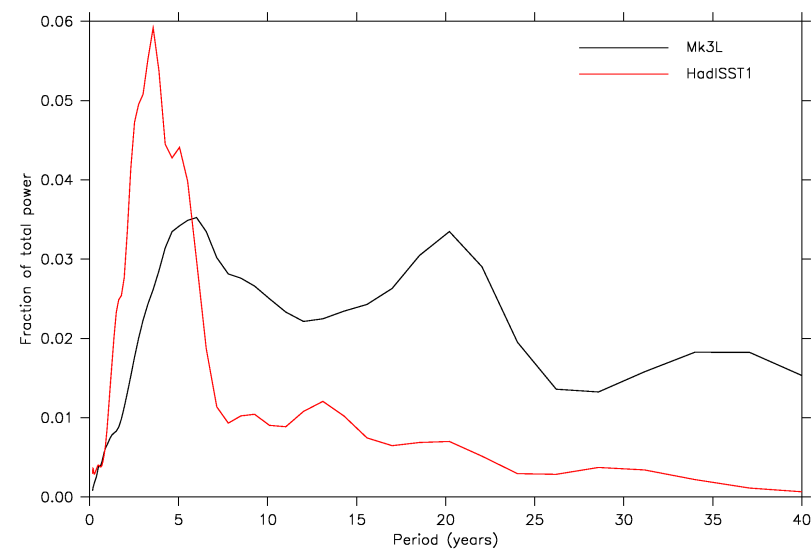

Fig. 18. The wavelet power spectrum of the Niño 3.4 sea surface temperature anomaly for Mk3L (black, years 201-1200) and the HadISST1 analysis (red, 1871-2003). Units are fraction of total power.

\section{Future development}

Future development work will address the deficiencies in the model climatology that have been identified herein. These deficiencies include both the biases in the control climatology, and the drift that is encountered within the coupled climate system model.

Biases in the mean state that are particularly significant include the excessive cloud cover and precipitation over the tropical oceans, deficiencies in the Northern Hemisphere sea ice cover, and the cold and fresh nature of the deep ocean. The simulated cloud cover and precipitation could 


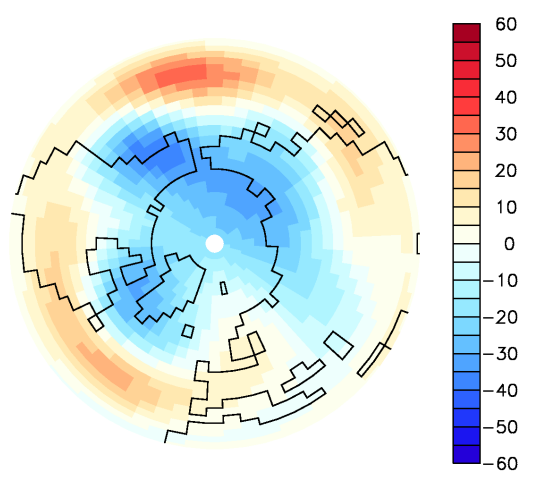

(a) Mk3L (NH)

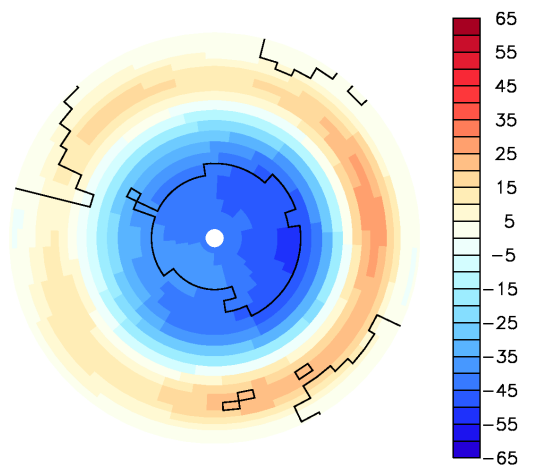

(c) Mk3L (SH)

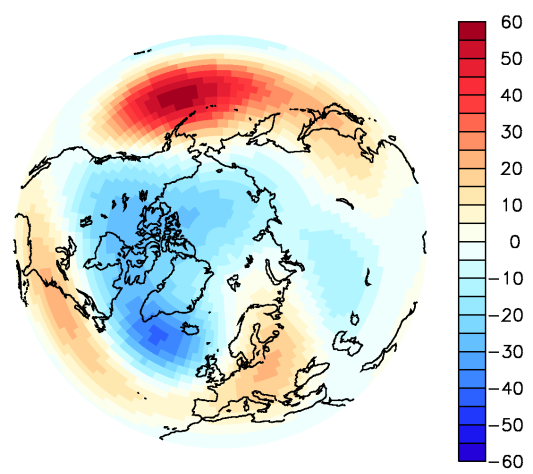

(b) NCEP2 (NH)

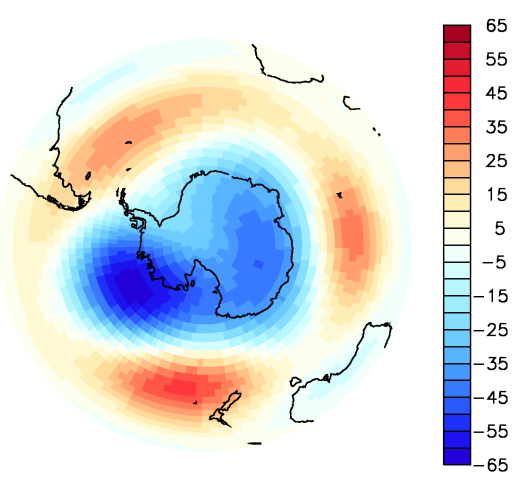

(d) NCEP2 (SH)

Fig. 19. The leading principal component of the monthly $500 \mathrm{hPa}$ geopotential height anomalies (m) for (a) Mk $3 \mathrm{~L}$ (years $201-1200,20^{\circ}-$

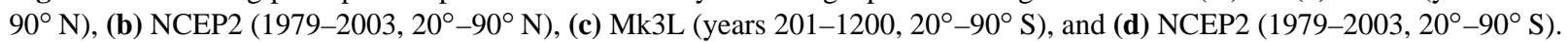

be improved through enhancements to the model physics, while the simulated sea ice cover and deep ocean could be improved through the use of better spin-up procedures.

The deficiencies in the simulated El Niño-Southern Oscillation should also be addressed. Although this could be achieved through an increase in the spatial resolution, this would impact upon the computational performance. Experience with other models has shown that a better representation of ENSO can alternatively be achieved through improvements to the parameterisation of atmospheric convection (Neale et al., 2008), or through reductions in the horizontal viscosity (Large et al., 2000) or vertical diffusivity (Meehl et al., 2001) used in the ocean.

Mk3L has a very stable control climatology, but there is a residual cooling trend that should be minimised. It is possible that this could be achieved by initialising the model with more realistic sea ice cover. Furthermore, the stability of the control climatology is achieved partly through the use of flux adjustments. This is inherently undesirable, and future development efforts will seek to produce a non-flux-adjusted version of the model that nonetheless has a stable and realistic control climatology.
Ongoing development work also seeks to upgrade physical schemes within the model, and to incorporate representations of additional components of the earth system. Future versions of Mk3L will include the CABLE land surface model (Kowalczyk et al., 2006), the CLM-DGVM dynamic global vegetation model (Levis et al., 2004), the ocean biogeochemistry model of Matear and Hirst (2003), and the tropospheric aerosol scheme of Rotstayn et al. (2007). A dynamic ice sheet model (e.g., Rutt et al., 2009) and simulation of stable isotopes (e.g., Noone and Simmonds, 2002) are also being considered for incorporation. These developments will transform Mk3L from a climate system model into an earth system model. This will allow it to be used to address a whole new class of scientific questions, such as the role of vegetation and carbon cycle feedbacks within the climate system, or the role of abrupt climate change.

\section{Conclusions}

The CSIRO Mk3L climate system model has been described and evaluated. The model is designed primarily for millennial-scale climate simulations, and includes 


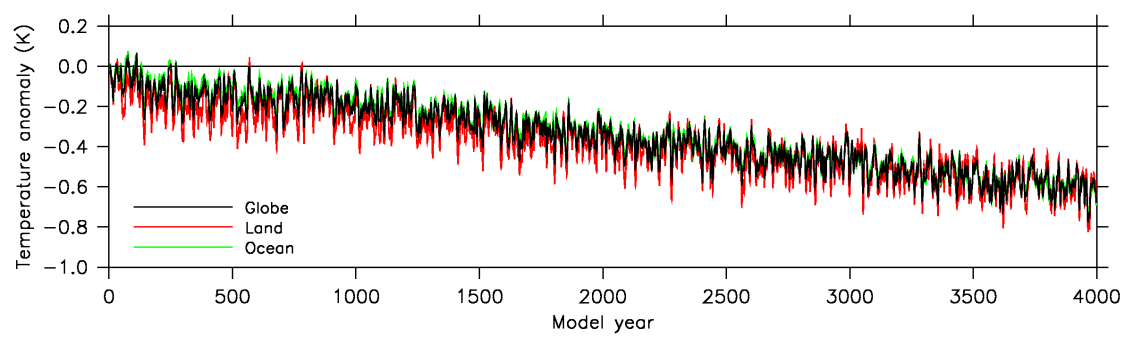

(a) Surface air temperature

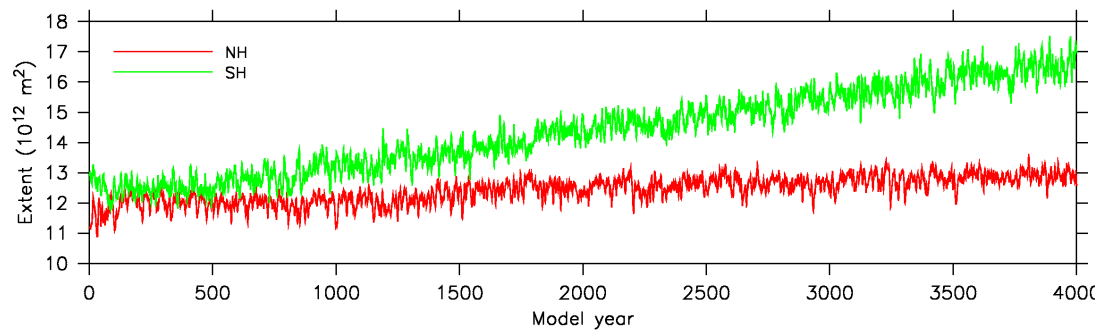

(b) Sea ice extent

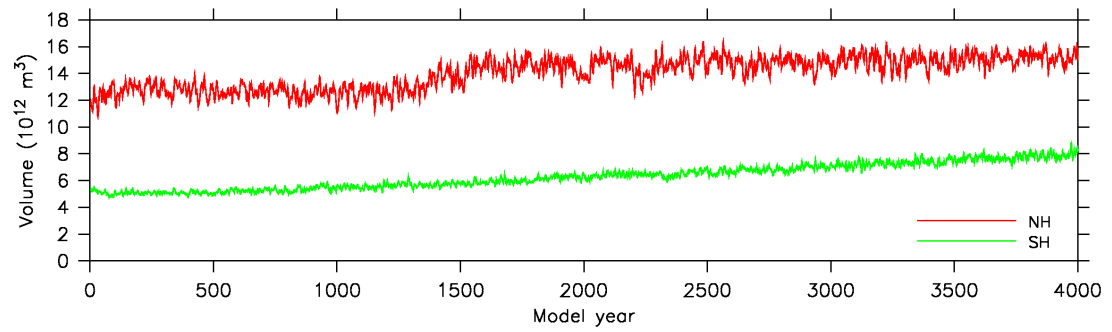

(c) Sea ice volume

Fig. 20. The drift in annual-mean surface air temperature, sea ice extent and sea ice volume: (a) surface air temperature, anomaly relative to the initial state, (b) sea ice extent, and (c) sea ice volume. The values shown are five-year running means.

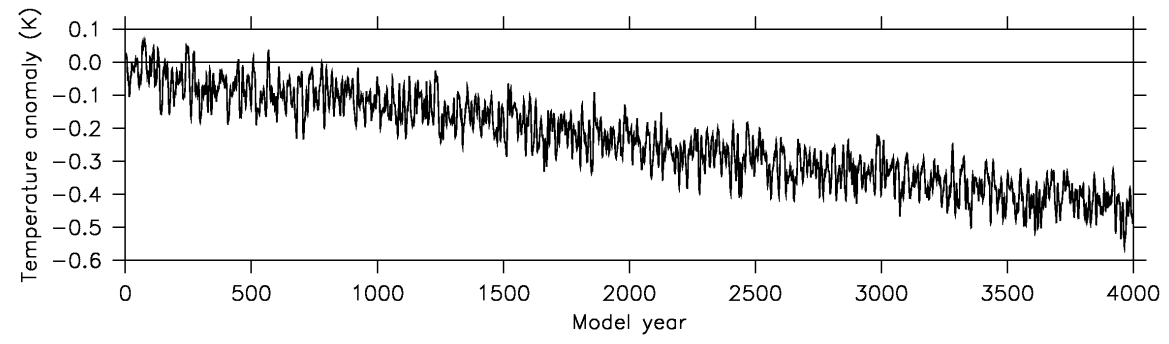

(a) Sea surface temperature

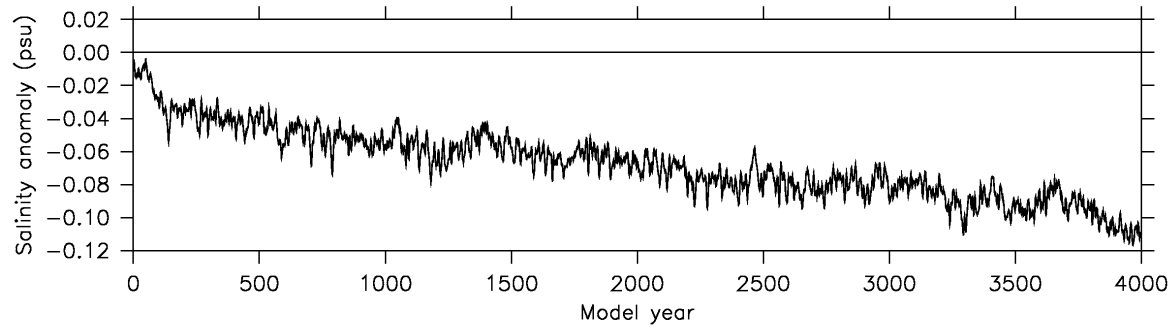

(b) Sea surface salinity

Fig. 21. The drift in annual-mean sea surface temperature and salinity: (a) sea surface temperature, and (b) sea surface salinity. The values shown are five-year running means, and are expressed as anomalies relative to the initial state. 


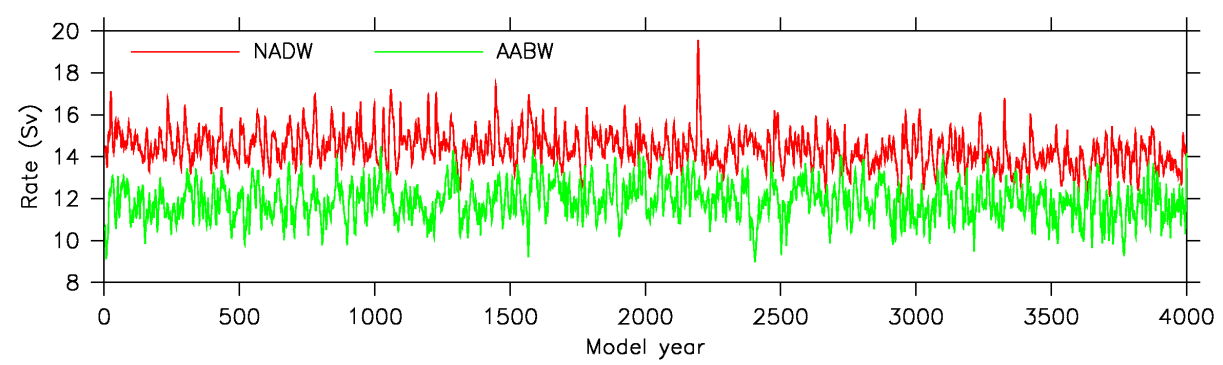

(a) Deep water formation

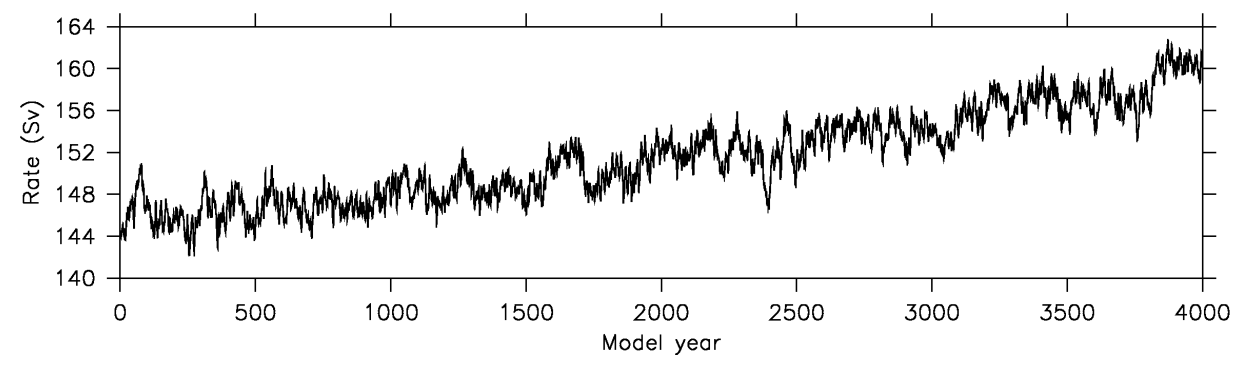

(b) Antarctic Circumpolar Current

Fig. 22. The rates of deep water formation, and the strength of the Antarctic Circumpolar Current: (a) the rates of formation of North Atlantic Deep Water (red) and Antarctic Bottom Water (green), and (b) the rate of volume transport through Drake Passage. The values shown are five-year running means.

representations of the atmosphere, ocean, sea ice and land surface. The model distribution is freely available to the research community.

The simulated surface air temperature, sea ice, cloud cover and precipitation exhibit broad agreement with observations. However, there are deficiencies in the Northern Hemisphere sea ice cover, associated with surface air temperatures which are too warm over Hudson Bay in winter. Other discrepancies in the simulated climate include excessive cloud cover over the tropical oceans, poor representation of marine stratocumulus, and regional biases in precipitation.

The simulated oceanic circulation is reasonable, with the strength of the Antarctic Circumpolar Current being in good agreement with observations. However, the rate of North Atlantic Deep Water formation is slightly too weak, the rate of Antarctic Bottom Water formation may be slightly too strong, and the western boundary currents are too weak and diffuse. The deep ocean is also too cold and too fresh.

The model produces reasonable representations of the leading modes of internal climate variability. The dominant mode of tropical climate variability is El Niño-Southern Oscillation, although the simulated ENSO is too weak, too slow, and characterised by excessive modulation on interdecadal timescales. The dominant modes of extratropical climate variability are the Northern and Southern Annular Modes. The geopotential height anomalies associated with each of these modes are reasonably well represented, although the simulated Southern Annular Mode exhibits an excessive zonal symmetry.
The model is found to exhibit a high degree of stability, with the global-mean surface air temperature cooling at a rate of just $0.015 \mathrm{~K}$ per century over the course of a $4000-\mathrm{yr}$ control simulation. This drift arises from changes in the Northern Hemisphere sea ice cover during the first century, and could potentially be avoided through improvements to the spin-up procedure. The strength of the thermohaline circulation exhibits no long-term trend.

Overall, the model has considerable utility for studying the behaviour of the larger-scale features of the climate system on millennial timescales. However, the reduced spatial resolution leads to some regional scale biases and some deficiencies in the nature of the simulated interannual climate variability. The residual long-term drift also limits the utility of the model for very long climate simulations. Future development work will seek to address deficiencies in the model climatology and to incorporate representations of additional components of the earth system.

\section{Appendix A}

The coupled climate system model simulation analysed herein is experiment $\mathrm{d} 73$. Years $201-1200$ of this experiment have been submitted to the PMIP2 database under experiment pmip2_0k_oa, with the model name CSIRO-Mk3L-1.0. 


\section{Supplementary material related to this article is available online at: http://www.geosci-model-dev.net/4/483/2011/ gmd-4-483-2011-supplement.pdf.}

Acknowledgements. The authors wish to acknowledge CSIRO Marine and Atmospheric Research for providing access to their climate model. Leon Rotstayn supplied reduced-resolution versions of the model components, while Dave Bi, Martin Dix, Hal Gordon, Tony Hirst, Eva Kowalczyk, Siobhan O'Farrell and Ian Watterson also contributed towards the development of Mk3L. Invaluable assistance was received from staff at the NCI National Facility (formerly the Australian Partnership for Advanced Computing), particularly Stuart Midgley and David Singleton. The authors also wish to acknowledge the many other people, too numerous to list here, who have contributed towards the development and release of Mk3L. Particular thanks are due to CSIRO Marine and Atmospheric Research and the Antarctic Climate and Ecosystems Co-operative Research Centre for allowing the model to be made freely available to the research community.

The lead author's contribution towards this work was performed as part of his $\mathrm{PhD}$ project. Financial support was received from the Australian Government (an International Postgraduate Research Scholarship), the University of Tasmania (a Tasmania Research Scholarship), the Antarctic CRC (an Antarctic CRC Top-Up Scholarship) and the Trans-Antarctic Association (grant TAA/99/12). Steven Phipps would like to thank Bill Budd, Nathan Bindoff, Jason Roberts, Scott Power, Xingren Wu and Tas van Ommen for their supervision and guidance throughout his candidature.

The development of Mk3L was supported by awards under the Merit Allocation Scheme on the NCI National Facility at the Australian National University. Grants of computer time were also received from the Tasmanian Partnership for Advanced Computing (Hobart, Tasmania) and iVEC (Perth, Western Australia). The authors wish to acknowledge use of the Ferret program for analysis and graphics in this paper (http://ferret.pmel.noaa.gov/Ferret/). The World Ocean Atlas 1998, NCEP-DOE Reanalysis 2 and NOAA Optimum Interpolation Sea Surface Temperature Analysis v2 were provided by the NOAA-ESRL Physical Sciences Division, Boulder, Colorado, USA from their website at http://www.esrl.noaa.gov/ psd/. The HadISST1 dataset was obtained from the Met Office Hadley Centre website at http://hadobs.metoffice.com/hadisst/.

Suggestions by Dave Thompson, Ian Watterson, Chris Jones and one anonymous referee have improved this manuscript.

Edited by: H. Goosse

\section{References}

AchutaRao, K. and Sperber, K. R.: Simulation of the El Niño Southern Oscillation: results from the Coupled Model Intercomparison Project, Clim. Dynam., 19, 191-209, 2002.

Arakawa, A. and Lamb, V. R.: Computational design of the basic dynamical processes of the UCLA general circulation model, in: General Circulation Models of the Atmosphere, edited by: Chang, J., vol. 17 of Methods in Computational Physics, Academic Press, New York, 173-265, 1977.
Barkstrom, B. R.: The Earth Radiation Budget Experiment (ERBE), B. Am. Meteorol. Soc., 65, 1170-1185, 1984.

Bell, J., Duffy, P., Covey, C., Sloan, L., and the CMIP investigators: Comparison of temperature variability in observations and sixteen climate model simulations, Geophys. Res. Lett., 27, 261264, 2000.

Berger, A. L.: Long-term variations of daily insolation and Quaternary climatic changes, J. Atmos. Sci., 35, 2362-2367, 1978.

Bernie, D. J., Guilyardi, E., Madec, G., Slingo, J. M., and Woolnough, S. J.: Impact of resolving the diurnal cycle in an oceanatmosphere GCM. Part 1: a diurnally forced OGCM, Clim. Dynam., 29, 575-590, 2007.

Bernie, D. J., Guilyardi, E., Madec, G., Slingo, J. M., Woolnough, S. J., and Cole, J.: Impact of resolving the diurnal cycle in an ocean-atmosphere GCM. Part 2: a diurnally coupled CGCM, Clim. Dynam., 31, 909-925, 2008.

Bi, D.: Transient and long-term behaviour of the world ocean under global warming, Ph.D. thesis, University of Tasmania, Hobart, Tasmania, Australia, 2002.

Bi, D., Budd, W. F., Hirst, A. C., and Wu, X.: Collapse and reorganisation of the Southern Ocean overturning under global warming in a coupled model, Geophys. Res. Lett., 28, 3927-3930, 2001.

Bi, D., Budd, W. F., Hirst, A. C., and Wu, X.: Response of the Antarctic Circumpolar Current transport to global warming in a coupled model, Geophys. Res. Lett., 29, 2173, doi:10.1029/2002GL015919, 2002.

Bretherton, C. S., Uttal, T., Fairall, C. W., Yuter, S. E., Weller, R. A., Baumgardner, D., Comstock, K., Wood, R., and Raga, G. B.: The EPIC 2001 stratocumulus study, B. Am. Meteorol. Soc., 85, $967-$ 977, 2004.

Brown, J., Collins, M., Tudhope, A. W., and Toniazzo, T.: Modelling mid-Holocene tropical climate and ENSO variability: towards constraining predictions of future change with palaeodata, Clim. Dynam., 30, 19-36, 2008.

Bryan, K.: A numerical method for the study of the circulation of the World Ocean, J. Comput. Phys., 4, 347-376, 1969.

Bryan, K.: Accelerating the convergence to equilibrium of oceanclimate models, J. Phys. Oceanogr., 14, 666-673, 1984.

Bryan, K., Manabe, S., and Pacanowski, R. C.: A global oceanatmosphere climate model. Part II. The oceanic circulation, J. Phys. Oceanogr., 5, 30-46, 1975.

Bryden, H. L.: New polynomials for thermal expansion, adiabatic temperature gradient and potential temperature of sea water, Deep-Sea Res., 20, 401-408, 1973.

Carmack, E. C.: Water characteristics of the Southern Ocean south of the Polar Front, Deep-Sea Res., 24, 15-41, 1977.

Cess, R. D. and Potter, G. L.: Exploratory studies of cloud radiative forcing with a general circulation model, Tellus, 39A, 460-473, 1987.

Chouinard, C., Béland, M., and McFarlane, N.: A simple gravity wave drag parameterization for use in medium-range weather forecast models, Atmos.-Ocean, 24, 91-110, 1986.

Claussen, M., Mysak, L. A., Weaver, A. J., Crucifix, M., Fichefet, T., Loutre, M.-F., Weber, S. L., Alcamo, J., Alexeev, V. A., Berger, A., Calov, R., Ganopoloski, A., Goosse, H., Lohmann, G., Lunkeit, F., Mokhov, I. I., Petoukhov, V., Stone, P., and Wang, Z.: Earth system models of intermediate complexity: closing the gap in the spectrum of climate system models, Clim. Dynam., 18, 579-586, 2002. 
Collins, W. D., Bitz, C. M., Blackmon, M. L., Bonan, G. B., Bretherton, C. S., Carton, J. A., Chang, P., Doney, S. C., Hack, J. J., Henderson, T. B., Kiehl, J. T., Large, W. G., McKenna, D. S., Santer, B. D., and Smith, R. D.: The Community Climate System Model version 3 (CCSM3), J. Climate, 19, 2122-2143, 2006.

Cox, M. D.: A primitive equation, 3-dimensional model of the ocean, GFDL Ocean Group Technical Report 1, Geophysical Fluid Dynamics Laboratory, Princeton University, Princeton, New Jersey, 1984.

Cox, M. D.: Isopycnal diffusion in a $z$-coordinate ocean model, Ocean Model., 74, 1-5, 1987.

Cox, P. M., Betts, R. A., Jones, C. D., Spall, S. A., and Totterdell, I. J.: Acceleration of global warming due to carbon-cycle feedbacks in a coupled climate model, Nature, 408, 184-187, 2000 .

Cubasch, U., Hasselmann, K., Höck, H., Maier-Reimer, E., Mikolajewicz, U., Santer, B. D., and Sausen, R.: Time-dependent greenhouse warming computation with a coupled atmosphere-ocean model, Clim. Dynam., 8, 55-69, 1992.

Cunningham, S. A., Alderson, S. G., King, B. A., and Brandon, M. A.: Transport and variability of the Antarctic Circumpolar Current in Drake Passage, J. Geophys. Res., 108, 8084, doi:10.1029/2001JC001147, 2003.

Danabasoglu, G., Large, W. G., Tribbia, J. T., Gent, P. R., Briegleb, B. P., and McWilliams, J. C.: Diurnal coupling in the tropical oceans of CCSM3, J. Climate, 19, 2347-2365, 2006.

Danabasoglu, G., Ferrari, R., and McWilliams, J. C.: Sensitivity of an ocean general circulation model to a parameterization of near-surface eddy fluxes, J. Climate, 21, 1192-1208, 2008.

Dixon, K. W., Delworth, T. L., Knutson, T. R., Spelman, M. J., and Stouffer, R. J.: A comparison of climate change simulations produced by two GFDL coupled climate models, Global Planet. Change, 37, 81-102, 2003.

England, M. H. and Hirst, A. C.: Chlorofluorocarbon uptake in a World Ocean model: 2. sensitivity to surface thermohaline forcing and subsurface mixing parameterizations, J. Geophys. Res., 102, 15709-15731, 1997.

Fels, S. B. and Schwarzkopf, M. D.: The simplified exchange approximation: a new method for radiative transfer calculations, J. Atmos. Sci., 32, 1475-1488, 1975.

Fels, S. B. and Schwarzkopf, M. D.: An efficient, accurate algorithm for calculating $\mathrm{CO}_{2} 15 \mu \mathrm{m}$ band cooling rates, J. Geophys. Res., 86, 1205-1232, 1981.

Flato, G. M. and Hibler III, W. D.: On a simple sea-ice dynamics model for climate studies, Ann. Glaciol., 14, 72-77, 1990.

Flato, G. M. and Hibler III, W. D.: Modeling pack ice as a cavitating fluid, J. Phys. Oceanogr., 22, 626-651, 1992.

Gargett, A. E.: Vertical eddy diffusivity in the ocean interior, J. Mar. Res, 42, 359-393, 1984.

Gates, W. L. and Nelson, A. B.: A new (revised) tabulation of the Scripps topography on a 1 degree global grid. Part I: terrain heights, Report R-1276-1-ARPA, The Rand Corporation, Santa Monica, California, available at: http://www.rand. org/pubs/reports/2009/R1276-1.pdf (last access: January 2011), 1975a.

Gates, W. L. and Nelson, A. B.: A new (revised) tabulation of the Scripps topography on a 1 degree global grid. Part II: ocean depths, Report R-1277-1-ARPA, The Rand Corpora- tion, Santa Monica, California, available at: http://www.rand. org/pubs/reports/2009/R1277-1.pdf (last access: January 2011), $1975 b$.

Gent, P. R. and McWilliams, J. C.: Isopycnal mixing in ocean circulation models, J. Phys. Oceanogr., 20, 150-155, 1990.

Gent, P. R., Willebrand, J., McDougall, T. J., and McWilliams, J. C.: Parameterizing eddy-induced tracer transports in ocean circulation models, J. Phys. Oceanogr., 25, 463-474, 1995.

Gill, A. E.: Circulation and bottom water formation in the Weddell Sea, Deep-Sea Res., 20, 111-140, 1973.

Gordon, A. L.: Interocean exchange of thermocline water, J. Geophys. Res., 91, 5037-5046, 1986.

Gordon, H. B.: A flux formulation of the spectral atmospheric equations suitable for use in long-term climate modeling, Mon. Weather Rev., 109, 56-64, 1981.

Gordon, H. B. and O'Farrell, S. P.: Transient climate change in the CSIRO coupled model with dynamic sea ice, Mon. Weather Rev., 125, 875-907, 1997.

Gordon, H. B., Rotstayn, L. D., McGregor, J. L., Dix, M. R., Kowalczyk, E. A., O'Farrell, S. P., Waterman, L. J., Hirst, A. C., Wilson, S. G., Collier, M. A., Watterson, I. G., and Elliott, T. I.: The CSIRO Mk3 Climate System Model, Technical Paper 60, CSIRO Atmospheric Research, available at: http://www.cmar. csiro.au/e-print/open/gordon_2002a.pdf (last access: January 2011), 2002.

Gregory, D. and Rowntree, P. R.: A mass flux convection scheme with representation of cloud ensemble characteristics and stability-dependent closure, Mon. Weather Rev., 118, 14831506, 1990.

Guilyardi, E.: El Niño-mean state-seasonal cycle interactions in a multi-model ensemble, Clim. Dynam., 26, 329-348, 2006.

Guilyardi, E., Wittenberg, A., Fedorov, A., Collins, M., Wang, C., Capotondi, A., van Oldenborgh, G. J., and Stockdale, T.: Understanding El Niño in ocean-atmosphere general circulation models, B. Am. Meteorol. Soc., 90, 325-340, 2009.

Hahn, C. J., Warren, S. G., and London, J.: The effect of moonlight on observation of cloud cover at night, and application to cloud climatology, J. Climate, 8, 1429-1446, 1995.

Hirst, A. C., O'Farrell, S. P., and Gordon, H. B.: Comparison of a coupled ocean-atmosphere model with and without oceanic eddy-induced advection. Part I: ocean spinup and control integration, J. Climate, 13, 139-163, 2000.

Holtslag, A. A. M. and Boville, B. A.: Local versus nonlocal boundary-layer diffusion in a global climate model, J. Climate, 6, 1825-1842, 1993.

Houghton, J. T., Ding, Y., Griggs, D. J., Noguer, M., van der Linden, P. J., Dai, X., Maskell, K., and Johnson, C. A. (eds.): Climate Change 2001: The Scientific Basis, Cambridge University Press, Cambridge, 2001.

Jones, C.: A fast ocean GCM without flux adjustments, J. Atmos. Ocean. Tech., 20, 1857-1868, 2003.

Jones, C., Gregory, J., Thorpe, R., Cox, P., Murphy, J., Sexton, D., and Valdes, P.: Systematic optimisation and climate simulation of FAMOUS, a fast version of HadCM3, Clim. Dynam., 25, 189204, 2005.

Kanamitsu, M., Ebisuzaki, W., Woollen, J., Yang, S.-K., Hnilo, J. J., Fiorino, M., and Potter, G. L.: NCEP-DOE AMIP-II reanalysis (R-2), B. Am. Meteorol. Soc., 83, 1631-1643, 2002.

Kitoh, A., Motoi, T., and Murakami, S.: El Niño-Southern Os- 
cillation simulation at $6000 \mathrm{yr}$ Before Present with the MRICGCM2.3: effect of flux adjustment, J. Climate, 20, 2484-2499, 2007.

Kowalczyk, E. A., Garratt, J. R., and Krummel, P. B.: A soilcanopy scheme for use in a numerical model of the atmosphere - 1D stand-alone model, Technical Paper 23, CSIRO Division of Atmospheric Research, available at: http://www.cmar.csiro.au/ e-print/open/kowalczyk_1991a.pdf (last access: January 2011), 1991.

Kowalczyk, E. A., Garratt, J. R., and Krummel, P. B.: Implementation of a soil-canopy scheme into the CSIRO GCM - regional aspects of the model response, Technical Paper 32, CSIRO Division of Atmospheric Research, available at: http://www.cmar. csiro.au/e-print/open/kowalczyk_1994a.pdf (last access: January 2011), 1994.

Kowalczyk, E. A., Wang, Y. P., Law, R. M., Davies, H. L., McGregor, J. L., and Abramowitz, G.: The CSIRO Atmosphere Biosphere Land Exchange (CABLE) model for use in climate models and as an offline model, CSIRO Marine and Atmospheric Research Paper 013, CSIRO Marine and Atmospheric Research, available at: http://www.cmar.csiro.au/e-print/open/ kowalczykea_2006a.pdf (last access: January 2011), 2006.

Lacis, A. A. and Hansen, J. E.: A parameterization for the absorption of solar radiation in the Earth's atmosphere, J. Atmos. Sci., 31, 118-133, 1974.

Lambert, S. J. and Boer, G. J.: CMIP1 evaluation and intercomparison of coupled climate models, Clim. Dynam., 17, 83-106, 2001.

Large, W. G., Danabasoglu, G., McWilliams, J. C., Gent, P. R., and Bryan, F. O.: Equatorial circulation of a global ocean climate model with anisotropic horizontal viscosity, J. Phys. Oceanogr., 31, 518-536, 2000.

Legates, D. R. and Willmott, C. J.: Mean seasonal and spatial variability in gauge-corrected, global precipitation, Int. J. Climatol., 10, 111-127, 1990.

Levis, S., Bonan, G. B., Vertenstein, M., and Oleson, K. W.: The Community Land Model's Dynamic Global Vegetation Model (CLM-DGVM): technical description and user's guide, NCAR Technical Note NCAR/TN-459+IA, National Center for Atmospheric Research, Boulder, Colorado, available at: http://nldr.library.ucar.edu/repository/assets/technotes/ asset-000-000-000-599.pdf (last access: January 2011), 2004.

Liu, Y., Liang, X. S., and Weisberg, R. H.: Rectification of the bias in the wavelet power spectrum, J. Atmos. Ocean. Tech., 24, 2093-2102, 2007.

Louis, J.-F.: A parametric model of vertical eddy fluxes in the atmosphere, Bound.-Lay. Meteorol., 17, 187-202, 1979.

Lubin, D., Jensen, E. H., and Gies, H. P.: Global surface ultraviolet radiation climatology from TOMS and ERBE data, J. Geophys. Res., 103, 26061-26091, 1998.

Marshall, G. J.: Trends in the Southern Annular Mode from observations and reanalyses, J. Climate, 16, 4134-4143, 2003.

Matear, R. J. and Hirst, A. C.: Long-term changes in dissolved oxygen concentrations in the ocean caused by protracted global warming, Global Biogeochem. Cy., 17, 1125, doi:10.1029/2002GB001997, 2003.

McGregor, J. L.: Economical determination of departure points for semi-Lagrangian models, Mon. Weather Rev., 121, 221-230, 1993.
Meehl, G. A., Boer, G. J., Covey, C., Latif, M., and Stouffer, R. J.: The Coupled Model Intercomparison Project (CMIP), B. Am. Meteorol. Soc., 81, 313-318, 2000.

Meehl, G. A., Gent, P. R., Arblaster, J. M., Otto-Bliesner, B. L., Brady, E. C., and Craig, A.: Factors that affect the amplitude of El Niño in global coupled climate models, Clim. Dynam., 17, 515-526, 2001.

Meehl, G. A., Covey, C., Delworth, T., Latif, M., McAvaney, B., Mitchell, J. F. B., Stouffer, R. J., and Taylor, K. E.: The WCRP CMIP3 multimodel dataset, B. Am. Meteorol. Soc., 88, 13831394, 2007.

Moore, A. M. and Reason, C. J. C.: The response of a global ocean general circulation model to climatological surface boundary conditions for temperature and salinity, J. Phys. Oceanogr., 23, 300-328, 1993.

Neale, R. B., Richter, J. H., and Jochum, M.: The impact of convection on ENSO: from a delayed oscillator to a series of events, J. Climate, 21, 5904-5924, 2008.

Noone, D. and Simmonds, I.: Associations between $\delta^{18} \mathrm{O}$ of water and climate parameters in a simulation of atmospheric circulation for 1979-1995, J. Climate, 15, 3150-3169, 2002.

Ocean Climate Laboratory: World Ocean Atlas 1998 CDROM documentation version 1.0, Internal Report 15, National Oceanographic Data Center, Silver Spring, Maryland, available at: ftp://ftp.nodc.noaa.gov/pub/data.nodc/woa/ PUBLICATIONS/NODC_Internal_Rpt_15.pdf (last access: January 2011), 1999.

O'Farrell, S. P.: Investigation of the dynamic sea ice component of a coupled atmosphere-sea ice general circulation model, J. Geophys. Res., 103, 15751-15782, 1998.

Olbers, D., Borowski, D., Völker, C., and Wölff, J.-O.: The dynamical balance, transport and circulation of the Antarctic Circumpolar Current, Antarct. Sci, 16, 439-470, 2004.

Orsi, A. H., Johnson, G. C., and Bullister, J. L.: Circulation, mixing, and production of Antarctic Bottom Water, Prog. Oceanogr., 43, 55-109, 1999.

Orsi, A. H., Jacobs, S. S., Gordon, A. L., and Visbeck, M.: Cooling and ventilating the abyssal ocean, Geophys. Res. Lett., 28, 2923 2926, 2001.

Parkinson, C. L., Cavalieri, D. L., Gloersen, P., Zwally, H. J., and Comiso, J. C.: Arctic sea ice extents, areas, and trends, 19781996, J. Geophys. Res., 104, 20837-20856, 1999.

Philander, S. G.: El Niño, La Niña, and the Southern Oscillation, Academic Press, San Diego, California, 1990.

Phipps, S. J.: The CSIRO Mk3L climate system model, Technical Report 3, Antarctic Climate and Ecosystems Cooperative Research Centre, Hobart, Tasmania, Australia, available at: http://www.acecrc.org.au/uploaded/117/797470_ 42phippscsiromk31.pdf (last access: January 2011), 2006a.

Phipps, S. J.: On long-term climate studies using a coupled general circulation model, Ph.D. thesis, University of Tasmania, Hobart, Tasmania, Australia, available at: http://eprints.utas.edu.au/ 2278/ (last access: January 2011), 2006b.

Rayner, N. A., Parker, D. E., Horton, E. B., Folland, C. K., Alexander, L. V., Rowell, D. P., Kent, E. C., and Kaplan, A.: Global analyses of sea surface temperature, sea ice, and night marine air temperature since the late nineteenth century, J. Geophys. Res., 108, 4407, doi:10.1029/2002JD002670, 2003. 
Reynolds, R. W., Rayner, N. A., Smith, T. M., Stokes, D. C., and Wang, W.: An improved in situ and satellite SST analysis for climate, J. Climate, 15, 1609-1625, 2002.

Robert, A. J.: The integration of a low order spectral form of the primitive meteorological equations, J. Meteorol. Soc. Jpn, 44, 237-244, 1966.

Rotstayn, L. D.: A physically based scheme for the treatment of stratiform clouds and precipitation in large-scale models. I: description and evaluation of the microphysical processes, Q. J. Roy. Meteorol. Soc., 123, 1227-1282, 1997.

Rotstayn, L. D.: A physically based scheme for the treatment of stratiform clouds and precipitation in large-scale models. II: comparison of modelled and observed climatological fields, Q. J. Roy. Meteorol. Soc., 124, 389-415, 1998.

Rotstayn, L. D., Ryan, B. F., and Katzfey, J. J.: A scheme for calculation of the liquid fraction in mixed-phase stratiform cloud in large-scale models, Mon. Weather Rev., 128, 1070-1088, 2000.

Rotstayn, L. D., Cai, W., Dix, M. R., Farquhar, G. D., Feng, Y., Ginoux, P., Herzog, M., Ito, A., Penner, J. E., Roderick, M. L., and Wang, M.: Have Australian rainfall and cloudiness increased due to the remote effects of Asian anthropogenic aerosols?, J. Geophys. Res., 112, D09202, doi:10.1029/2006JD007712, 2007.

Rutt, I. C., Hagdorn, M., Hulton, N. R. J., and Payne, A. J.: The Glimmer community ice sheet model, J. Geophys. Res., 114, F02004, doi:10.1029/2008JF001015, 2009.

Sausen, R., Barthel, K., and Hasselmann, K.: Coupled oceanatmosphere models with flux correction, Clim. Dynam., 2, 145163, 1988.

Schott, F. A., Lee, T. N., and Zantopp, R.: Variability of structure and transport of the Florida Current in the period range of days to seasonal, J. Phys. Oceanogr., 18, 1209-1230, 1988.

Schwarzkopf, M. D. and Fels, S. B.: Improvements to the algorithm for computing $\mathrm{CO}_{2}$ transmissivities and cooling rates, J. Geophys. Res., 90, 10541-10550, 1985.

Schwarzkopf, M. D. and Fels, S. B.: The simplified exchange method revisited: an accurate, rapid method for computation of infrared cooling rates and fluxes, J. Geophys. Res., 96, 90759096, 1991.

Semtner Jr., A. J.: A model for the thermodynamic growth of sea ice in numerical investigations of climate, J. Phys. Oceanogr., 6, 379-389, 1976.

Smethie Jr., W. M. and Fine, R. A.: Rates of North Atlantic Deep Water formation calculated from chlorofluorocarbon inventories, Deep-Sea Res. Pt. I, 48, 189-215, 2001.

Smith, I.: Global climate modelling within CSIRO: 1981 to 2006, Aust. Meteorol. Mag., 56, 153-166, 2007.

Solomon, S., Qin, D., Manning, M., Chen, Z., Marquis, M., Averyt, K. B., Tignor, M., and Miller, H. L. (eds.): Climate Change 2007: The Physical Science Basis, Cambridge University Press, Cambridge, 2007.

Stammer, D., Wunsch, C., Giering, R., Eckert, C., Heimbach, P., Marotzke, J., Adcroft, A., Hill, C. N., and Marshall, J.: Volume, heat, and freshwater transports of the global ocean circulation 1993-2000, estimated from a general circulation model constrained by World Ocean Circulation Experiment (WOCE) data, J. Geophys. Res., 108, 3007, doi:10.1029/2001JC001115, 2003.
Terray, L.: Sensitivity of climate drift to atmospheric physical parameterizations in a coupled ocean-atmosphere general circulation model, J. Climate, 11, 1633-1658, 1998.

Thompson, D. W. J. and Wallace, J. M.: The Arctic Oscillation signature in the wintertime geopotential height and temperature fields, Geophys. Res. Lett., 25, 1297-1300, 1998.

Thompson, D. W. J. and Wallace, J. M.: Annular modes in the extratropical circulation. Part I: month-to-month variability, J. Climate, 13, 1000-1016, 2000.

Torrence, C. and Compo, G. P.: A practical guide to wavelet analysis, B. Am. Meteorol. Soc., 79, 61-78, 1998.

Trenberth, K. E., Jones, P. D., Ambenje, P., Bojariu, R., Easterling, D., Tank, A. K., Parker, D., Rahimzadeh, F., Renwick, J. A., Rusticucci, M., Soden, B., and Zhai, P.: Observations: surface and atmospheric climate change, in: Climate Change 2007: The Physical Science Basis, edited by: Solomon, S., Qin, D., Manning, M., Chen, Z., Marquis, M., Averyt, K. B., Tignor, M., and Miller, H. L., Chap. 3, Cambridge University Press, Cambridge, 235-336, 2007.

Wadhams, P.: Ice in the Ocean, Gordon and Breach Science Publishers, New York, 2000.

Wang, W.-C., Liang, X.-Z., Dudek, M. P., Pollard, D., and Thompson, S. L.: Atmospheric ozone as a climate gas, Atmos. Res., 37, 247-256, 1995.

Warren, S. G., Hahn, C. J., London, J., Chervin, R. M., and Jenne, R. L.: Global distribution of total cloud cover and cloud type amounts over land, NCAR Technical Note NCAR/TN273+STR, National Center for Atmospheric Research, Boulder, Colorado, 1986.

Warren, S. G., Hahn, C. J., London, J., Chervin, R. M., and Jenne, R. L.: Global distribution of total cloud cover and cloud type amounts over the ocean, NCAR Technical Note NCAR/TN317+STR, National Center for Atmospheric Research, Boulder, Colorado, 1988.

Washington, W. M. and Parkinson, C. L.: An Introduction to ThreeDimensional Climate Modeling, Oxford University Press, Oxford, 1986.

Weaver, A. J. and Hughes, T. M. C.: On the incompatibility of ocean and atmosphere models and the need for flux adjustments, Clim. Dynam., 12, 141-170, 1996.

Weaver, A. J., Duffy, P. B., Eby, M., and Wiebe, E. C.: Evaluation of ocean and climate models using present-day observations and forcing, Atmos.-Ocean, 38, 271-301, 2000.

Worby, A. P., Geiger, C. A., Paget, M. J., Van Woert, M. L., Ackley, S. F., and DeLiberty, T. L.: Thickness distribution of Antarctic sea ice, J. Geophys. Res., 113, C05S92, doi:10.1029/2007JC004254, 2008.

Yeager, S. G., Shields, C. A., Large, W. G., and Hack, J. J.: The low-resolution CCSM3, J. Climate, 19, 2545-2566, 2006. 